University of Wollongong

Research Online

University of Wollongong in Dubai - Papers

University of Wollongong in Dubai

$1-1-2020$

\title{
Corrosion resistance of electrified railway tunnels made of steel fibre reinforced concrete
}

Kangkang Tang

Brunel University London, University of Wolverhampton

Stephen Wilkinson

University of Wollongong in Dubai, stephenwilkinson@uowdubai.ac.ae

Follow this and additional works at: https://ro.uow.edu.au/dubaipapers

\section{Recommended Citation}

Tang, Kangkang and Wilkinson, Stephen: Corrosion resistance of electrified railway tunnels made of steel fibre reinforced concrete 2020.

https://ro.uow.edu.au/dubaipapers/1095

Research Online is the open access institutional repository for the University of Wollongong. For further information contact the UOW Library: research-pubs@uow.edu.au 


\title{
Corrosion resistance of electrified railway tunnels made of steel fibre reinforced concrete
}

\begin{abstract}
Steel fibre reinforced concrete (SFRC) has been widely used in the construction of buildings, roads and bridges where high compressive and/or tensile strength is preferred. From a structural perspective, SFRC is an ideal substitute for conventional steel reinforcement in railway tunnel construction. However, it is still not clear whether discontinuous steel fibres can pick up and transfer stray current, especially stray alternating current (AC), and lead to similar corrosive attacks as occur in conventional steel reinforcement. The development of suitable approaches for the assessment of the corrosion susceptibility of SFRC under stray AC conditions is a primary aim of this paper. The analytical model, validated by experimental data, indicates that SFRC has an inherent corrosion resistance to stray AC due to the electrical double layer developed on the steel surface. The presence of a small amount of chlorides $(0.3 \mathrm{~mol} / \mathrm{L}$ in the concrete pore solution or $2 \%$ by mass of cement) however reduces its corrosion resistance.
\end{abstract}

\section{Keywords}

Steel fibre reinforced concrete

EIS

Potentiostatic

Galvanostatic

Passivity

SEM

\section{List of notations}

A: $\quad$ Exposed anode area of a working electrode $\left(\mathrm{cm}^{2}\right)$

$\beta_{a}, \beta_{b}: \quad$ Anodic and cathodic Tafel constants/gradients

$C_{f}: \quad$ Steel passive layer capacitance CPE $\left(\mathrm{S} \cdot \mathrm{S}^{\mathrm{n}} \cdot \mathrm{cm}^{-2}\right)$

$C_{d l}: \quad$ Double layer capacitance CPE $\left(\mathrm{S} \cdot \mathrm{S}^{\mathrm{n}} \cdot \mathrm{cm}^{-2}\right)$

$C: \quad$ Capacitance $(\mu \mathrm{F})$ 


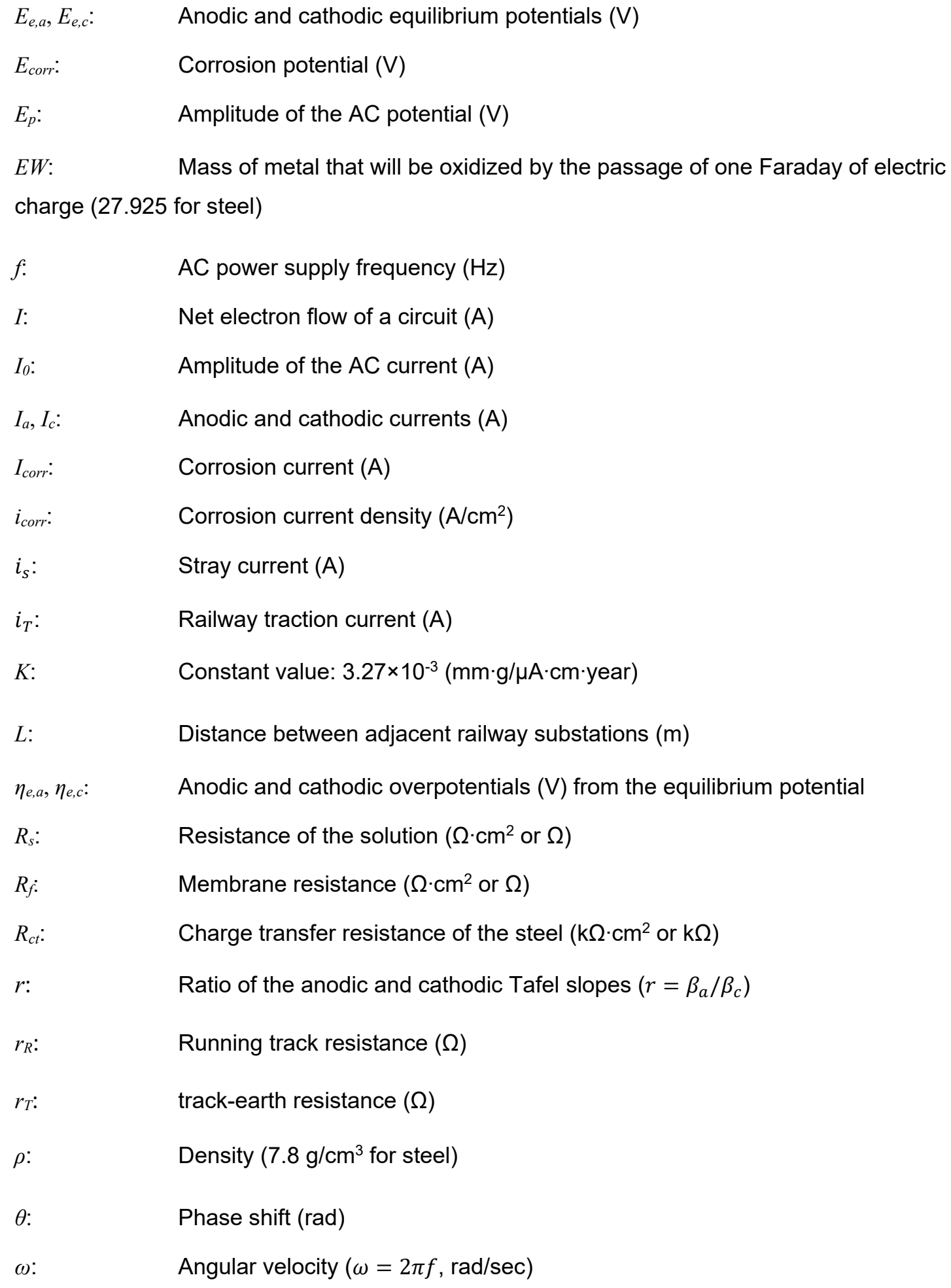




\section{Introduction}

$25 \mathrm{kV}$ alternating current (AC) electrification is popularly used in railway electrification and it has become an international standard for high-speed rail [1]. For high-speed rail, the power transmission is normally provided by the National Grid through a step-down transformer to a railway overhead contact line. The return circuit is achieved through the running rail which are connected to nearby substations. This process is schematically shown in Fig. 1. Partly concealed railway tunnels can effectively reduce noise and visual impacts during the construction and use of a railway. As a result, the Crossrail project consists of 26 miles of tunnels, accounting for $22 \%$ of the total length [2]; the High Speed 2 project consists of 56 miles of tunnels, accounting for $47 \%$ of the total length [3]; the TGV Turin-Lyon high-speed railway consists of a 36 miles of tunnels, accounting for $21 \%$ of the total length [4]; the Swiss New Rail Link through the Alps (NRLA) consists of the world's longest and deepest railway tunnel, i.e. the Gotthard Base Tunnel, with a total length of 35.5 miles [5]. In railway tunnel construction, precast concrete segmental linings are popularly used to ensure the overall stability and water tightness. For instance, over 200,000 concrete segments, each weighing over 3 tonnes and joined to form a ring, were used in the Crossrail project [2].

For an electrified railway, stray current refers to the current which disperses directly into the ground through the running track. The leakage of stray current to surrounding structures, e.g. reinforced concrete sleepers and lining segment, pushes electrons from the steel reinforcement surface and lead to its corrosion [6]. Alongside the development of modern high-speed rail networks, the corrosive damage due to stray current is becoming more prominent. Approximately $£ 600$ million is required per annum for the rehabilitation and repair of transportation infrastructure in the UK alone [7]. The prevention and mitigation of stray current induced corrosion will form an important element of the design, construction and operation of electrified railways.

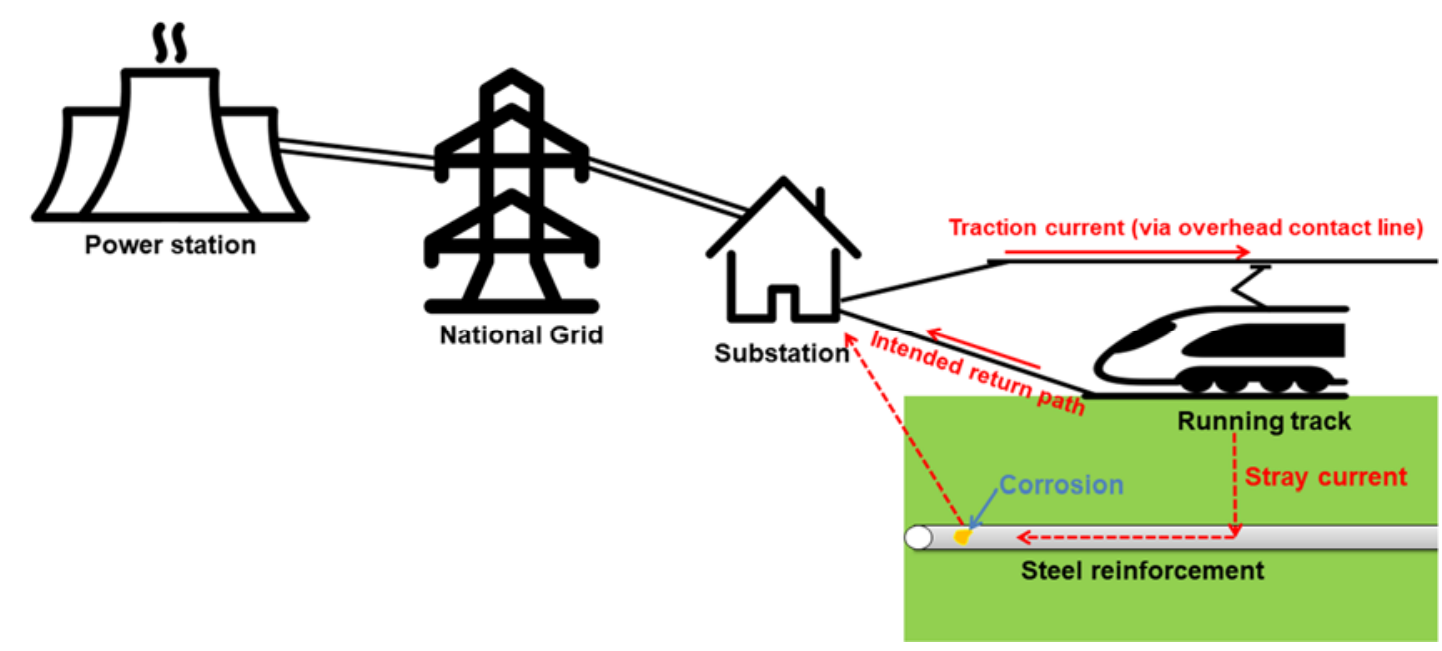

Fig. 1. Schematic of high-speed railway electrification and stray current induced corrosion 
Stray direct current (DC) induced corrosion is a long-recognized problem which led to a court judgment in 1893 (National Telephone Company versus Graff-Baker) recognising that stray current is inevitable, but attempting to limit its extent [8]. In comparison, the influence of stray alternating current $(\mathrm{AC})$ is considered less critical and stray $A C$ induced corrosion has only been reported more recently, alongside the development of high-speed rail. In 1986, serious corrosion was identified on the surface of buried pipelines in parallel with a $15 \mathrm{kV} \mathrm{AC}$ powered railway in Germany [9]. Thereafter, more cases of stray AC attack to pipelines were reported in France and North America [10, 11]. BS EN 15280 [12], evaluation of AC corrosion likelihood of buried pipelines, states that the severity of $A C$-induced corrosion depends primarily on the AC current density. This agrees with the findings by Kuang and Cheng [13] who reported that $30 \mathrm{~mA} / \mathrm{cm}^{2}$ can be taken as the AC threshold current density for steel corrosion within an alkaline environment $(\mathrm{pH}=9.6)$, which was achieved using a $\mathrm{NaHCO}_{3}$ and $\mathrm{Na}_{2} \mathrm{CO}_{3}$ solution. Alongside this, both $\mathrm{pH}$ and conductivity of the electrolyte was found to increase with time under externally applied AC [13]. This effect of alkalisation was attributed to the oxygen reduction reaction during the negative half waves of $A C$ applied [14]. During the positive half waves, steel dissolution $F_{e} \rightarrow F_{e}^{2+}+2 e$ is expected when the current leaves the steel surface. It should be noted that the above results were obtained using aqueous electrolytes [14]. For steel reinforcement, concrete performs as a solid electrolyte whose microstructures, e.g. as represented by permeability and porosity, change with time [15]. Based on a review of the literature, it is not clear whether the detrimental effect of AC-induced corrosion can be mitigated alongside the maturity of concrete with time.

The corrosion behaviour of steel reinforced concrete subject to an AC current can become complicated due to the presence of chlorides. In ordinary steel reinforced concrete, chloride ions are a common cause of steel reinforcement corrosion. The critical chloride threshold for corrosion initiation in conventional steel reinforced concrete is reported to vary between 0.15 and $0.6 \%$ (by mass of cement) [16]. A much higher chloride threshold of $2 \%$ (by mass of cement) was reported for SFRC, indicating enhanced corrosion resistance [17]. A combined effect of $A C$ currents and chloride significantly reduce the chloride threshold of steel. Brenna [18] reported that the chloride threshold is reduced by more than $50 \%$ due to the presence of a $5 \mathrm{~mA} / \mathrm{cm}^{2}$ AC current. It is however not clear whether this finding is applicable for SFRC which contains discontinuous steel reinforcement.

In order to quantitatively assess the intensity of AC-induced corrosion, Cao [19] developed a mathematical model for the prediction of the steel anodic current $\left(I_{a}\right)$ which is directly related to the corrosion state of steel under $\mathrm{AC}$ interference:

$I_{a}=I_{\text {corr }} \cdot \sum_{n=0}^{\infty} \frac{\left(\frac{E p}{2 \beta a}\right)^{2}}{(n !)^{2}}+I_{c o r r} \cdot \sum_{k=0}^{\infty} A_{1} \cdot \sin (2 k+1) \omega t+I_{\text {corr }} \cdot \sum_{k=1}^{\infty} A_{2} \cdot \cos 2 k \omega t$

Both $A_{1}$ and $A_{2}$ are constant. A linear integration of $I_{a}$ (positive parts only) with respect to time $(t)$ gives a total electric charge (coulombs), upon which the material loss can be calculated. As 
the second and third parts of Eq. (1) are periodic functions and their integrations over one period $(2 \pi / \omega)$ is zero; only the first part of Eq. (1) is responsible for the AC-induced corrosion and it is primarily affected by the magnitude of the $\mathrm{AC}$ voltage $\left(E_{p}\right)$ and the anodic Tafel slope $\left(\beta_{a}\right)$. This conclusion was based on the assumption that the anodic half cycle during $\mathrm{AC}$ interference can be completely reversed during the cathodic half cycle. This however can lead to a flawed result because $\mathrm{O}_{2}$ reduction or $\mathrm{H}_{2}$ evolution is still more favoured than the reduction reaction of steel ions during the cathodic half circle. In order to consider the anodic and cathodic half circles respectively, Lalvani and Lin [20] proposed an electrochemical model representing the steel-electrolyte interface. This model consists of a double layer capacitor $\left(C_{d l}\right)$ and a polarization resistor $\left(R_{p}\right)$ in a parallel arrangement. It is subjected to a sum of a DC voltage $\left(E_{D C}\right)$ and an $A C$ voltage $\left(E_{A C}\right)$ and $E_{A C}=E_{p} \cdot \sin \omega t$. The mathematical solution of the total current allows both half cycles over one period under $E_{A C}$ to be taken into consideration. This was based on a root-mean-square current $\left(i_{\text {r.m.s. }}\right)$ proposed by the authors [20]:

$i_{\text {r.m.s. }}^{2}=\frac{1}{2 \pi / \omega} \int_{0}^{2 \pi / \omega} i^{2} d t$

$i$ represents the total current that flows through the circuit. The mathematical derivation of Eq. (2) is presented as:

$i_{\text {r.m.s. }}^{2}=\frac{a_{0}^{2}}{2}+a_{1}^{2} \sum_{K=0}^{\infty} \frac{1}{(K !)^{2}}\left(\frac{E_{p}}{\beta_{a}}\right)^{2 K}-2 a_{1} a_{2} \sum_{K=0}^{\infty} \frac{1}{(K !)^{2}}\left[\left(\frac{1}{\beta_{a}}+\frac{1}{\beta_{c}}\right)\left(\frac{E_{p}}{2}\right)\right]^{2 K}+a_{2}^{2} \sum_{K=0}^{\infty} \frac{1}{(K !)^{2}}\left(\frac{E_{p}}{\beta_{c}}\right)^{2 K}$

The Faradaic current which passes $R_{p}$ is determined as:

$i_{\text {f.r.m.s. }}^{2}=a_{1}^{2} \sum_{K=0}^{\infty} \frac{1}{(K !)^{2}}\left(\frac{E_{p}}{\beta_{a}}\right)^{2 K}-2 a_{1} a_{2} \sum_{K=0}^{\infty} \frac{1}{(K !)^{2}}\left[\left(\frac{1}{\beta_{a}}+\frac{1}{\beta_{c}}\right)\left(\frac{E_{p}}{2}\right)\right]^{2 K}+a_{2}^{2} \sum_{K=0}^{\infty} \frac{1}{(K !)^{2}}\left(\frac{E_{p}}{\beta_{c}}\right)^{2 K}$

Where: $a_{0}=\omega C_{d l} E_{p} ; a_{1}=i_{c o r r, D C} \cdot \exp \left(\frac{E_{D C}-E_{c o r r}, D C}{\beta_{a}}\right) ; a_{1}=i_{c o r r, D C} \cdot \exp \left(\frac{E_{D C}-E_{c o r r, D C}}{\beta_{c}}\right)$.

Eq. (4) shows that the Faradaic current $\left(i_{f . r . m . s .}\right)$, which governs the steel corrosion rate $(C R)$, is independent of the frequency $(\omega)$. This conclusion however is not supported by the experimental data published by Wang et al. [21]: $C R$ is a strong function of $\omega$. Bosch and Bogaerts [22] developed a revised mathematical model for the prediction of anodic current based on Butler-Volmer equation (Eq. (5)).

$I=I_{a}-I_{c}=I_{c o r r}\left[\exp \left(\frac{\mathrm{E}-E_{c o r r}}{\beta_{a}}\right)-\exp \left(-\frac{\mathrm{E}-E_{c o r r}}{\beta_{c}}\right)\right]$

Through expansion via a modified Bessel function, the authors [22] concluded that corrosion potential $\left(E_{c o r r}\right)$ shifts more negatively when $r<1$ and the $C R$ increases at any value of $r$ under a kinetically controlled process. $r$ represents the ratio of the anodic and cathodic Tafel slopes, or $r=\beta_{a} / \beta_{c}$. Under a thermal dynamically controlled redox process, $E_{c o r r}$ decreases with increasing $A C$ voltage amplitude $\left(E_{p}\right)$ and the rate of decrease depends on the ratio of $i_{c o r r} / i_{L} . i_{c o r r}$ represents the corrosion current density; $i_{L}$ is the limiting diffusion current density of 
oxygen reduction [22]. However, the $C R$ was still independent of the angular velocity of the applied AC voltage $(\omega)$ under both processes according to the mathematical model [22]. This indicates that frequency dependent processes such as double layer charging cannot be sufficiently considered by the above models. In addition to this limitation, anodic and cathodic Tafel slopes $\left(\beta_{a}\right.$ and $\beta_{c}$ ) and their ratio $(r)$ change under an externally applied potential and this cannot be sufficiently addressed by the above models either.

In addition to electrochemical modelling, scanning electron microscope (SEM) analysis has been increasingly used to qualitatively evaluate steel reinforcement corrosion. Previous investigations based on SEM [13, 18, 23-26] indicate that the severity of steel corrosion heavily depends on the current density of the AC current $\left(I_{p}\right)$ applied. Wen et al. [24] reported an exponential relationship between $A C$ current densities and the resulting steel corrosion pit numbers: $y=a \cdot i^{-b}$ where $y$ represents the total pit numbers observed; both $a$ and $b$ are constants. This shows the potential to quantitatively evaluate steel corrosion through SEM. Sara et al. [26] investigated the mitigation effect of corrosion inhibitors on AC-induced corrosion based on SEM. Electrolytes containing $\mathrm{HCl}$ and $\left(\mathrm{CH}_{2}\right)_{6} \mathrm{~N}_{4}$ (hexamethylenetetramine) were found to lead to denser and more uniform corrosion products on the steel surface, enhancing the corrosion resistance of steel. Fu et al. [14] applied positive and negative half circles of AC signals separately to steel samples (in aqueous electrolytes) for half an hour. Serious pitting corrosion was observed on the steel samples after the positive half circles. There was however no sign of corrosion on the steel samples after the negative half circles based on SEM results, indicating only positive half circles are responsible for steel corrosion. It should be noted that negative half circles of AC can lead to the accumulation of electrons on the steel surface which eventually results in the break-down of the steel passive layer [12]. It will lead to an underestimate for the evaluation of AC-induced corrosion by considering the positive half circles only.

The popularity of using steel fibres as a substitute for conventional steel reinforcement in infrastructure projects has increased internationally, owing to the publication of the fib Model Code 2010 which provides design guidelines for SFRC [27]. In the UK, the first steel fibre reinforced segmental lining tunnel was the London Heathrow Airport baggage tunnel built in 1995 [28]; the first large-scale application of SFRC segments was the Channel Tunnel Rail Link project in 2003 [29]. As a part of the London Underground, SFRC segmental linings were used in the Jubilee line extension project [28]. Steel fibres, in conjunction with polypropylene fibres, will be used as the primary reinforcement material in the UK High Speed 2 (HS2) tunnel segmental lining construction. Some other reference projects are shown in Table 1. However, the application of SFRC in railway projects outside the UK is still scarce. The 'Guangzhou Metro Line 3' project in China aimed to use SFRC as the primary tunnel lining material but this plan was rejected due to the uncertainties concerning stray current induced corrosion [30]. To allow the safe application of SRFC, there is a pressing need for a validated 
approach to determine the corrosion susceptibility of SFRC, especially under a stray AC environment.

Table 1 Reference projects of SFRC tunnels (outside the UK) [28, 31-34]

\begin{tabular}{l|l|l|l|l}
\hline & $\begin{array}{l}\text { Year } \\
\text { accomplished }\end{array}$ & $\begin{array}{l}\text { Total length } \\
\mathbf{( k m )}\end{array}$ & Usage & Location \\
\hline Oenzberg tunnel & 2003 & 3.2 & Sewer & Switzerland \\
\hline Copenhagen heating tunnel & 2005 & 3.9 & Utility sector & Denmark \\
\hline Gold Coast desalination plant & 2009 & 2 & Utility sector & Australia \\
\hline $\begin{array}{l}\text { Strategic Tunnel Enhancement } \\
\text { Programme (STEP) }\end{array}$ & 2015 & 42 & Sewer & Abu Dhabi \\
\hline $\begin{array}{l}\text { Red Line South of the Doha metro } \\
\text { system }\end{array}$ & 2019 & 42.8 & $\begin{array}{l}\text { Metro tunnel } \\
\text { ling segments }\end{array}$ & Qatar \\
\hline $\begin{array}{l}\text { Cityringen Branch to Nordhavn } \\
\text { tunnel }\end{array}$ & 2019 & 3.4 & $\begin{array}{l}\text { Metro tunnel } \\
\text { ling segments }\end{array}$ & Denmark \\
\hline Belchen tunnel & 2021 & 3.2 & $\begin{array}{l}\text { Highway tunnel } \\
\text { ling segments }\end{array}$ & Switzerland \\
\hline
\end{tabular}

\section{Experimental and analytical procedures}

Alternating current (AC) traction power systems account for $64 \%$ of the UK electrified railway network [35]. However based on a review of the literature, it is still controversial whether stray AC currents can be picked up and transferred by discrete and discontinuous steel fibres. The primary objective of this work is to develop a suitable approach for the evaluation of the corrosion susceptibility of SFRC under stray AC conditions. This enables the uncertainties concerning the corrosion initiation and the corrosion rate $(C R)$ measurement in SFRC to be clarified. A galvanostatic (controlled electric current) polarization technique was developed for the modelling of stray AC current using laboratory equipment. This is according to Li's model which was developed for the calculation of stray current $\left(i_{S}\right)$ [36]:

$i_{S}=\frac{1}{12} i_{T} \frac{r_{R}}{r_{T}} L^{2}$

In this model, $i_{S}$ is governed by railway traction current $\left(i_{T}\right)$, resistance of the running tracks $\left(r_{R}\right)$, track-earth resistance $\left(r_{T}\right)$ and the distance between substations $(L)$. The typical spacing between DC feeding substations $(L)$ is 1.5 to $2 \mathrm{~km}$ for $750 \mathrm{VDC}$ traction systems and 3 to 4 $\mathrm{km}$ for $1.5 \mathrm{kV} \mathrm{DC}$ and $15 \mathrm{kV} \mathrm{AC}$ traction systems [37]. A constant $i_{S}$ is therefore expected when a standard track-and-earth insulation is maintained. This has been followed in this work and controlled-current (galvanostatic) polarization was adopted to simulate stray AC interference to SFRC segmental linings.

In reinforced concrete, the concrete performs as a solid electrolyte and its porous structure allows ions (e.g. $\mathrm{OH}^{-}$) and molecules (e.g. $\mathrm{O}_{2}$ ) to come in contact with the reinforcement. In this work, aqueous electrolytes based on saturated $\mathrm{Ca}(\mathrm{OH})_{2}$ were used to represent concrete for the investigation of stray current induced corrosion in SFRC due to its high cost efficiency $[38,39]$. Reagent grade $\mathrm{NaCl}$ was added into the saturated $\mathrm{Ca}(\mathrm{OH})_{2}$ solution at different concentrations $(0,0.3,0.6$ and $0.8 \mathrm{~mol} / \mathrm{L}$ or $\mathrm{M})$, representing different working conditions [40]. 
The permeation properties and porous structure of concrete were represented using a high density upholstery foam beam, which soaked up the simulated concrete pore solutions. This is discussed in Section 2.1. The effect of stray AC on the corrosion behaviour was also investigated using the simulated concrete pore solutions and this is discussed in Section 2.2. In order to verify that the results were applicable for solid electrolytes, mortar mixes were used for the investigation of $\mathrm{AC}$-induced corrosion and the experimental procedure is discussed in Section 2.3.

All electrochemical tests discussed in this paper were conducted inside an environmental chamber which was set at a constant temperature $\left(20^{\circ} \mathrm{C}\right)$ and humidity $(90 \%)$. The environmental chamber also performed as a Faraday cage as the exterior and interior parts were made from stainless steel and connected to earth. It can protect the interior from electromagnetic interference from the outside.

\subsection{Study of the corrosion behaviour of steel fibres without AC interference}

The steel fibre used in this work was provided in bags by Bekaert. This cold drawn low carbon steel fibre is $62 \mathrm{~mm}$ in length and $0.75 \mathrm{~mm}$ in diameter. Steel fibres were ground by 2000 grit emery paper and rinsed in deionized water again prior to testing. All steel fibres were preconnected to a copper cable to facilitate the electrochemical tests. The steel-copper connection was coated with a hot melt polymer adhesive to prevent galvanostatic corrosion, allowing an approximate exposed surface area $1.4 \mathrm{~cm}^{2}$ of the tested steel fibre.

A 3-electrode electrochemical cell (Fig. 2) was developed for the Tafel polarization test using a Gamry Interface 1000E potenitostat. The steel fibre was used as the working electrode (WE) and its electrode potential was measured with regards to a silver/silver chloride $(\mathrm{Ag} / \mathrm{AgCl})$ reference electrode $(\mathrm{RE}$, with filling solution $3 \% \mathrm{KCl}$ ) which was placed on the top surface of the foam beam. During Tafel polarization, a constant potential scanning rate, $1 \mathrm{mV} / \mathrm{sec}$, was applied to the WE and the potential ranged of -250 to $+250 \mathrm{mV}$ (vs OCP). The current flow between the WE and counter electrode (CE), i.e. a $40 \times 50 \times 3 \mathrm{~mm}$ graphite plate, was measured by the potentiostat. Such a slow potential scanning rate allowed the nonlinear correlation between externally applied potential $(E)$ and the current density $i(i=I / A)$ response to be measured. Tafel slope analysis was conducted to determine the corrosion current density $\left(i_{c o r r}\right)$ and corrosion potential $\left(E_{\text {corr }}\right)$ based on a nonlinear regression between the applied potential $(E)$ and the current density $i(i=I / A)$. Three parallel samples were prepared and tested in each group based on freshly prepared electrodes and electrolytes. Results are discussed in Section 3.1. 


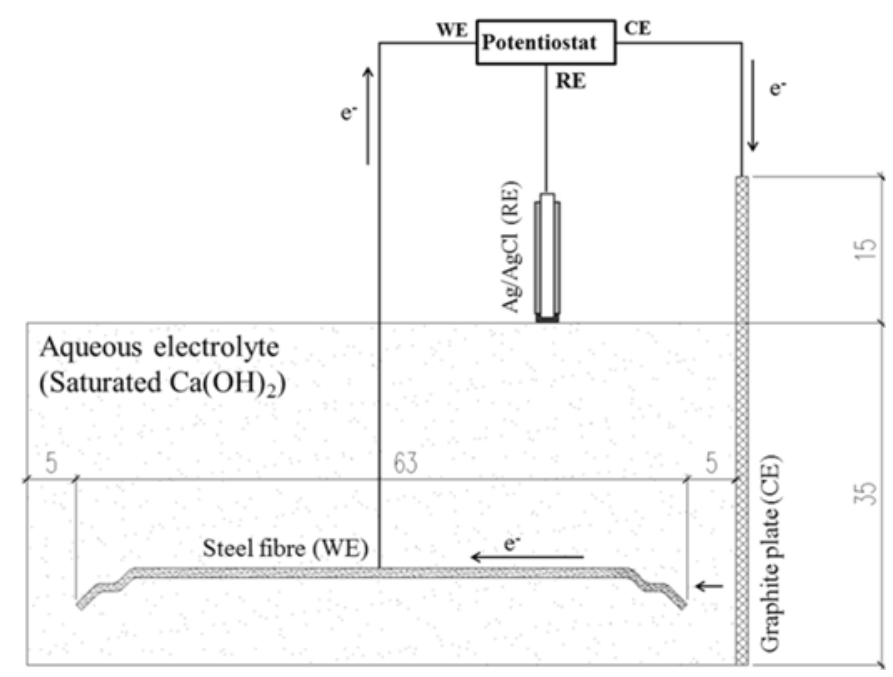

Fig. 2. Tafel polarization test using simulated concrete pore solutions (all units in $\mathrm{mm}$ )

\subsection{Study of the AC interference effect on steel fibre}

Based on a review of the published research [41], the magnitude of stray AC current density is in range between 10 and $50 \mathrm{~mA} / \mathrm{cm}^{2}$. This has been followed in this work and a sine wave current perturbation of $30 \mathrm{~mA}\left(\approx 21 \mathrm{~mA} / \mathrm{cm}^{2}\right)$ was applied to the working electrode (Fig. 3 ) for 1-hr when the externally applied potential $(E)$ was measured. The AC frequency $(f)$ was same as the UK National Grid AC frequency, i.e. $50 \mathrm{~Hz}$. Such a constant frequency AC perturbation was achieved using the Gamry Interface 1000E potentiostat with the Gamry's Virtual Front Panel (VFP600) software package. After 1-hr AC polarization, the Tafel polarization test was conducted to determine the corrosion current density $\left(i_{\text {corr }}\right)$ and corrosion potential $\left(E_{c o r r}\right)$ following the same procedure as discussed in Section 2.1. The results are discussed in Section 3.2.

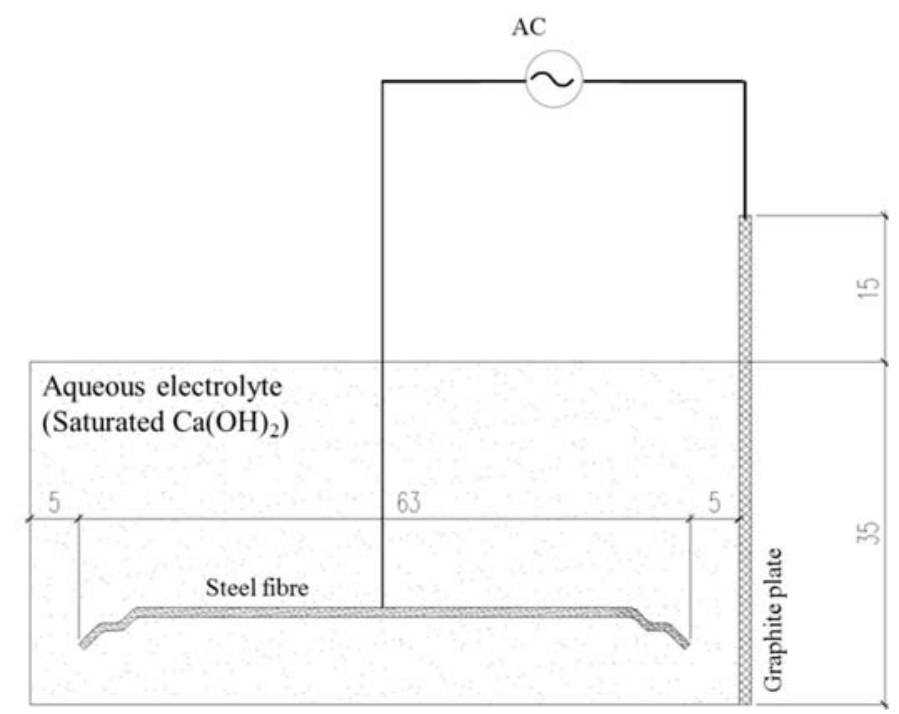

Fig. 3. AC polarization test (all units in $\mathrm{mm}$ ) 


\subsection{Study of the solid electrolyte (mortar) effect on the corrosion behaviour of SFRC}

In order to verify that the results (e.g. $E_{\text {corr }}$ and $i_{c o r r}$ ) obtained using simulated concrete pore solutions were applicable for SFRC, mortar mixes were used as a solid electrolyte and the mix proportions are shown in Table 2. An electrolytic cell, as seen in Fig. 4, was developed for the evaluation of the corrosion susceptibility of SFRC. It drives coupled redox reactions between the anode (+) and cathode (-) through the application of alternating currents which simulate stray AC interference. A twin-fibre system was developed and it enlarged the exposed surface area of steel fibres (i.e. approximately $2.8 \mathrm{~cm}^{2}$ ), allowing for a uniform transmission of electrical signals between the anode $(+)$ and cathode $(-)$ due to the high impedance solid electrolyte (i.e. mortar) used. 4 graphite plates, $40 \times 50 \times 3 \mathrm{~mm}$, were embedded into the electrolyte to close the electrical circuit. The gap between steel fibres and graphite plates was maintained as $5 \mathrm{~mm}$. Chloride can lead to serious localized corrosion or pitting corrosion by breaking down the steel passive layer. The presence of chloride in concrete can be a result of contaminated aggregate, mixing water or the diffusion of chloride ions alongside the anodic reaction $\mathrm{Fe} \rightarrow \mathrm{Fe}^{2+}+2 e^{-} .2 \% \mathrm{NaCl}$ (by mass of cement) was added into the concrete mixture to approximate the working condition of a railway tunnel in direct contact with seawater [42]. Two different interfering conditions were considered in the same specimen:

- AC interference group: SFRC samples containing 0 or $2 \% \mathrm{NaCl}$ (by mass of cement), and subjected to $60 \mathrm{~mA}\left(I_{p}\right) \mathrm{AC}$ current for $72 \mathrm{hrs}$ between the age of 1 and 4 days after casting.

- Reference group: SFRC samples containing 0 or $2 \% \mathrm{NaCl}$ (by mass of cement) without pre-exposure to $A C$ interference.

All SFRC specimens were placed in the environmental chamber set at $20^{\circ} \mathrm{C}$ and $90 \%$ humidity. A sine wave current perturbation of $60 \mathrm{~mA}$ (or $21.4 \mathrm{~mA} / \mathrm{cm}^{2}$ ) was applied to the AC interference group for 72 hours when the externally applied potential $(E)$ was measured. The AC current was applied using the Gamry Interface 1000E potentiostat with the Gamry's Virtual Front Panel (VFP600) software package. With the maturity of the mortar, the impedance $(|Z|)$ of mortar increases and this requires a higher $\mathrm{AC}$ voltage $\left(E_{p}\right)$ to push the electrons through the cell. As a result, $E_{p}$ was found to increase from about $3 \mathrm{~V}$ ( 1 day after casting) to over $12 \mathrm{~V}$ at the age of 4 days to maintain $I_{p}(=60 \mathrm{~mA})$ under a chloride free condition. As the Gamry potentiostat used in this project has a safe DC or AC limit up to $10 \mathrm{~V}$, the duration of $A C$ interference study was maintained as 72 hours. The reference group was cast alongside the $A C$ polarization group but without direct exposure to $A C$ interference.

Electrochemical impedance spectroscopy (EIS) was conducted at an age of 1, 4, 10 and 50 days after casting to evaluate the effect of $A C$ interference on the corrosion susceptibility of embedded steel fibres. EIS was conducted by applying a small sinusoidal potential, $E_{p}$. $\sin (\omega t)$, to the electrochemical cell about the OCP to the WE (i.e. steel fibre). $E_{p}$ was 
maintained as $25 \mathrm{mV}$ and EIS was swept at frequencies varying between $10^{5}$ and $10^{-1} \mathrm{~Hz}$, with 10 measurements per decade or per order of magnitude. Such a small voltage perturbation does not change the electrochemical properties of the electrolyte or electrode. This makes EIS a non-destructive testing method, allowing for a long-term corrosion monitoring of reinforced concrete [43-47]. An $\mathrm{Ag} / \mathrm{AgCl}$ reference electrode (RE) was placed near the WE to monitor the electrode potential. A sponge saturated with $\mathrm{Ca}(\mathrm{OH})_{2}$ solution was placed between the RE and the mortar, ensuring a good electrical connection between the RE and the mortar. The steel-copper cable connection was coated with a hot melt polymer adhesive to prevent galvanostatic corrosion. The impedance of the electrochemical cell $(Z)$ was determined as the correlation between the applied potential $(E)$ and the measured current $(I)$ and results were presented as Bode and Nyquist plots. The interpretation of EIS data was based on the best-fit results obtained through equivalent electrical circuit modelling and this is discussed in Section 3.3.

Table 2 Mortar mix proportions

\begin{tabular}{ccccc}
\hline Mortar mixes & $\begin{array}{c}\text { CEM I 52,5 } \\
\left(\mathrm{kg} / \mathrm{m}^{3}\right)\end{array}$ & Free W/C & $\begin{array}{c}\text { Sand }(0-4 \mathrm{~mm}) \\
\left(\mathrm{kg} / \mathrm{m}^{3}\right)\end{array}$ & $\begin{array}{c}\mathrm{NaCl} \\
\left(\mathrm{kg} / \mathrm{m}^{3}\right)\end{array}$ \\
\hline $0 \% \mathrm{NaCl}$ & 480 & 0.35 & 1814 & 0 \\
\hline $2 \% \mathrm{NaCl}$ & 480 & 0.35 & 1814 & 9.6 \\
\hline
\end{tabular}

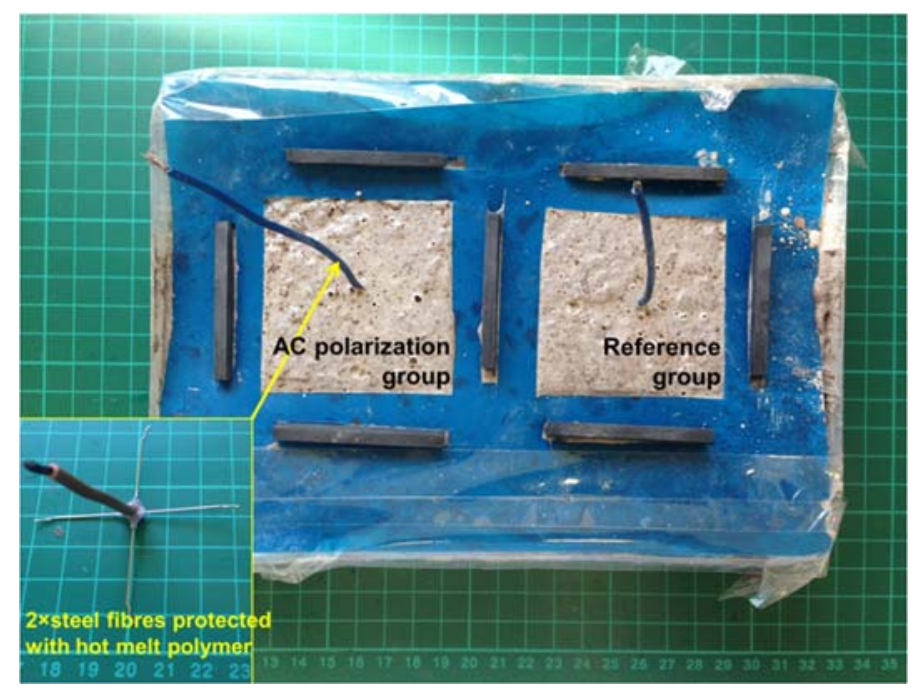

(a) AC polarization and control group 


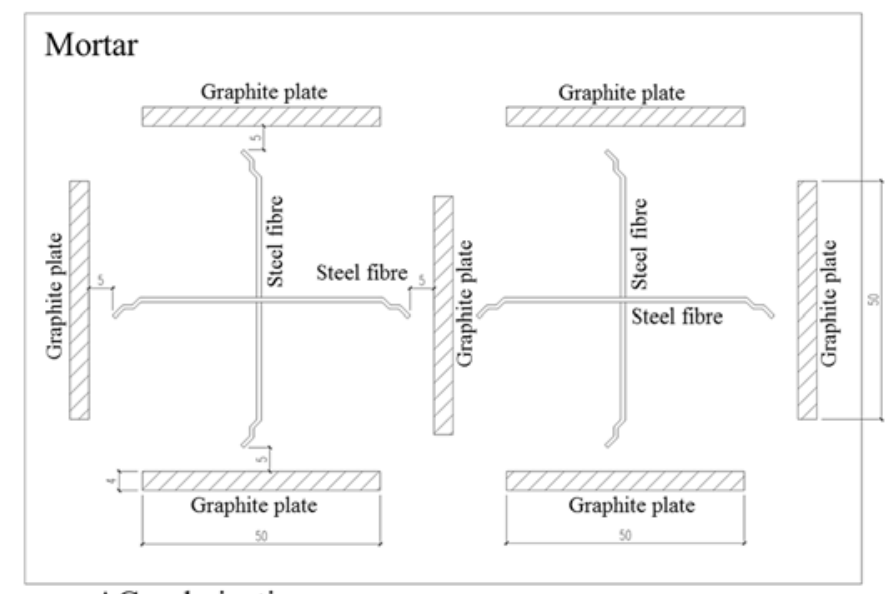

AC polarization group Reference group

(b) Plan view

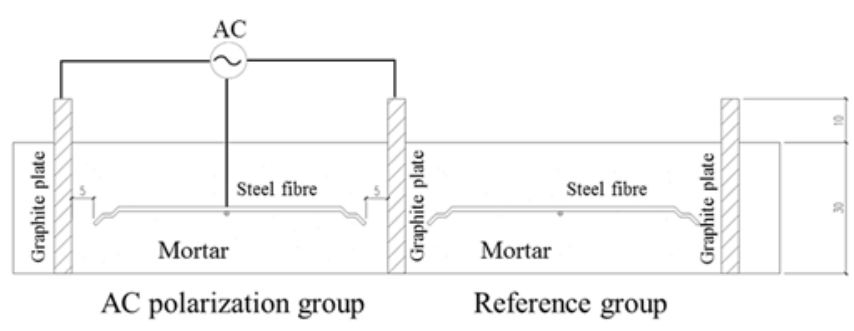

(c) Elevation

Fig. 4. SFRC AC polarization test

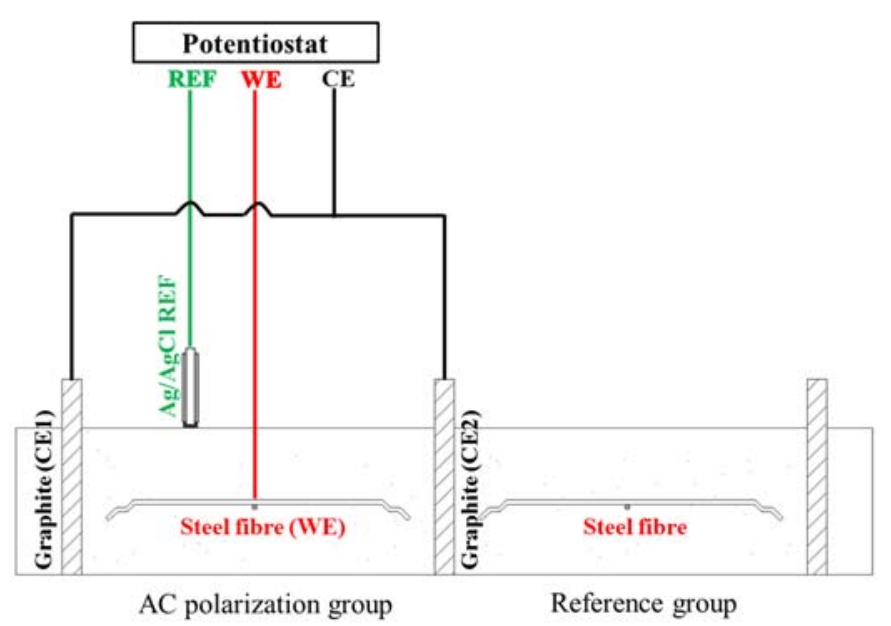

Fig. 5. Schematic of SFRC EIS test (all units in $\mathrm{mm}$ )

\subsection{Morphology study of AC induced corrosion in SFRC}

A morphology study was performed on the $A C$ interference group and reference group at the age of 50 days. SFRC samples were cut at a distance of $2.5 \mathrm{~cm}$ from the centre of the steel fibre (Fig. 6) using a diamond saw to expose the steel fibre cross sections. Thereafter, the 
morphology study of the steel fibre cross sections was performed using a Zeiss EVO50 SEMEDS. Samples for SEM analysis were mounted on standard stubs using double sides sticky carbon tabs. The samples were not dried prior to imaging, but would have experienced some air drying during transport. No evidence of surface damage was observed due to gas escape from the sample within the electron microscope. Energy Dispersive X-Ray Spectroscopy (EDS) allows the identification of the elemental composition of a point line or area which is visible in the electron microscope. This allows a combined qualitative visual and quantitative elemental analysis of corroded steel fibres. The emission of X-Rays is a random process, so EDS spectra contain noise. With repeated passes across the region of interest the amount of noise is reduced. For this work 50 passes were used to ensure the quality of the elemental data. Results are discussed in Section 3.4.

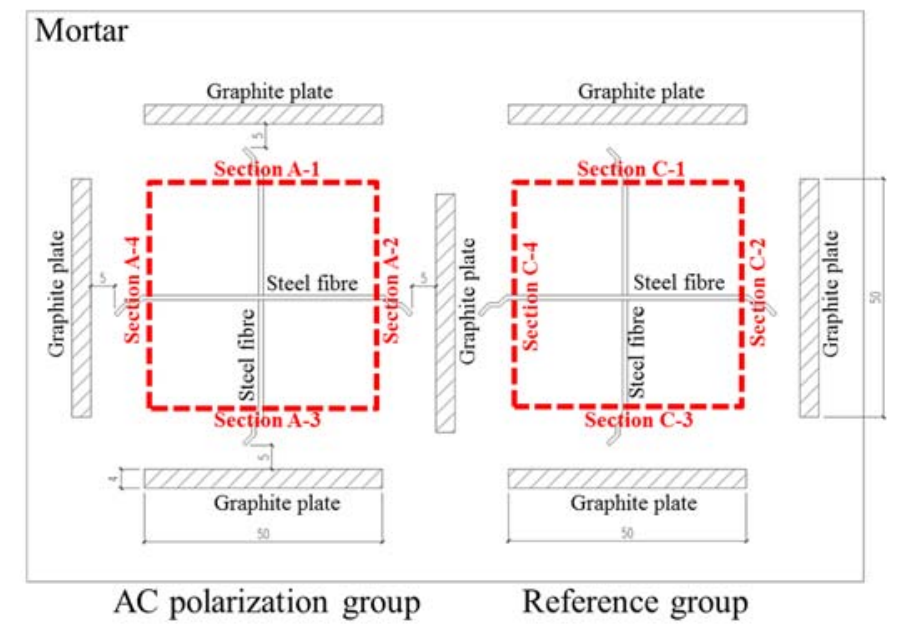

Fig. 6. SFRC specimen sections for SEM

\section{Results and discussion}

\subsection{Corrosion behaviour of steel fibres without AC interference}

The Tafel polarization results are presented as curves between the electrode potential $E$ (vs $\mathrm{Ag} / \mathrm{AgCl} \mathrm{RE})$ and the current density $i(i=I / A)$ on a logarithmic scale (Fig. 7). $A$ represents the exposed surface area of the steel fibre to the electrolyte, i.e. $1.4 \mathrm{~cm}^{2}$. A nonlinear regression analysis based on Butler-Volmeter equation (Eq. (5)) was conducted to determine $i_{c o r r}$ and corrosion potential $\left(E_{c o r r}\right)$ using the Gamry Echem Analyst software package [48]. The best-fit results for $i_{c o r r}$ and $E_{\text {corr }}$ are shown in Fig. 8. It shows that $E_{\text {corr }}$ shifts more negatively due to the presence of $\mathrm{NaCl}$ in the electrolyte. On the other hand, $i_{\text {corr }}$ increases steadily from $5.4 \mu \mathrm{A} / \mathrm{cm}^{2}$ in a chloride-free environment to $72.2 \mu \mathrm{A} / \mathrm{cm}^{2}$ with $0.8 \mathrm{~mol} / \mathrm{L}$ in the electrolyte, indicating serious steel corrosion. In summary, the presence of chlorides, especially at high concentrations ( $\geq 0.6 \mathrm{~mol} / \mathrm{L}$ ), seriously enhances steel fibre corrosion. 


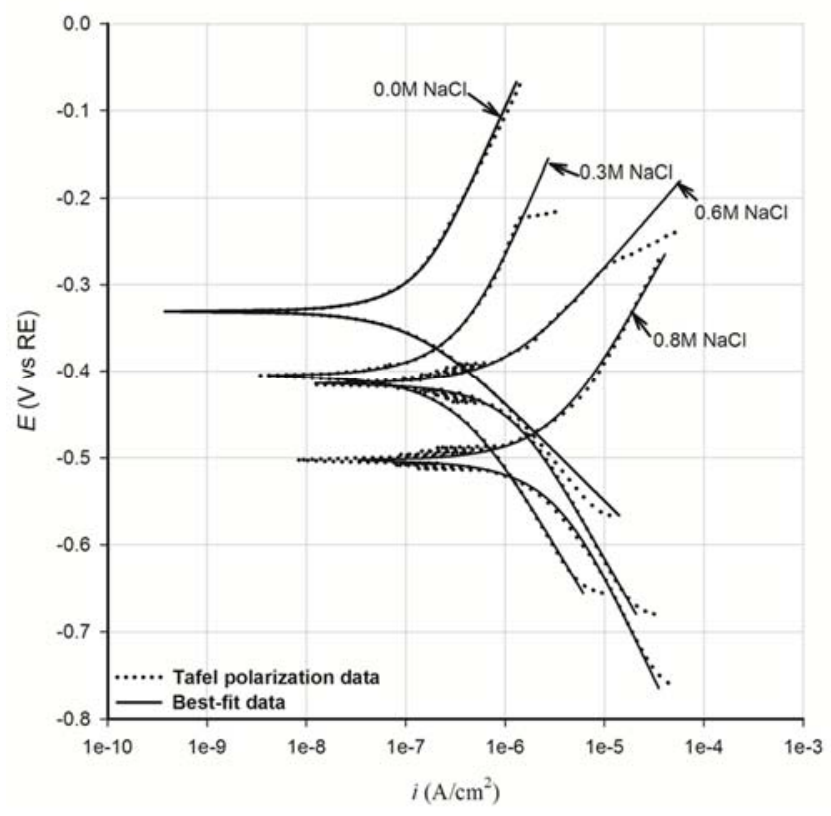

Fig. 7. Tafel polarization results ( $E-i$ curve)

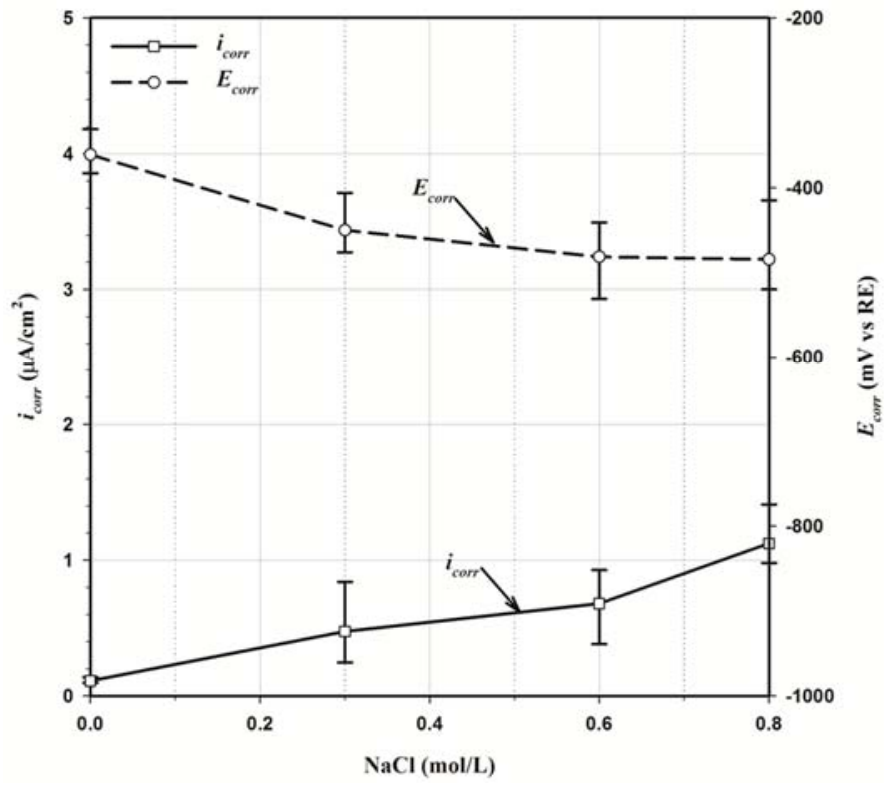

Fig. 8. Tafel polarization results ( $i_{c o r r}$ and $\left.E_{\text {corr }}\right)$

\subsection{AC interference effect on steel fibre}

When direct current electricity (DC) is used for electrolysis, positively charged ions (e.g. $\mathrm{H}^{+}$or $\mathrm{Fe}^{2+}$ ) are reduced at the cathode (-) while the negatively charged ions (e.g. $\mathrm{Cl}^{-}$or $\mathrm{OH}^{-}$) are oxidized at the anode (+). Electrolysis is of vital importance to chemistry and manufacturing to obtain elements from their naturally ionic compound form. The application of $A C$ electricity for electrolysis is rarely investigated due to a practical issue: the anodic half cycle during AC interference may be reversed during the cathodic half cycle. When the positive half cycle of 
an AC signal is scanned through the steel fibre, an oxidation reaction at the anode (steel) occurs alongside the development of the steel passive layer:

$F_{e} \rightarrow F_{e}^{2+}+2 e^{-}$

When the positive half cycle is applied to the graphite electrode, the following electrolytic reactions can also occur:

$2 \mathrm{Cl}^{-} \rightarrow \mathrm{Cl}_{2}+2 e^{-}$

$4 \mathrm{OH}^{-} \rightarrow \mathrm{O}_{2}+2 \mathrm{H}_{2} \mathrm{O}+4 e^{-}$

$2 \mathrm{H}_{2} \mathrm{O} \rightarrow \mathrm{O}_{2}+4 \mathrm{H}^{-}+4 e^{-}$

During the electrolyte of brine (i.e. saturated $\mathrm{Ca}(\mathrm{OH})_{2}$ and $\mathrm{NaCl}$ ), air bubbles were observed on the graphite electrodes in conjunction with a consistent bleach smell. This can be attributed to the chloride oxidation to chlorine gas (Eq. (8)) which prevails due to the slow kinetically controlled half-cell reactions associated with $\mathrm{O}_{2}$ evolution (e.g. Eq. (9) and (10)) in a chloride environment. During the negative half cycle of an AC signal, $\mathrm{H}_{2} \mathrm{O}$ and $\mathrm{O}_{2}$ reduction reactions (Eq. (11) and (12)) are both expected from an energetic point of view:

$2 \mathrm{H}_{2} \mathrm{O}+2 e^{-} \rightarrow \mathrm{H}_{2}+2 \mathrm{OH}^{-}$

$\mathrm{O}_{2}+2 \mathrm{H}_{2} \mathrm{O}+4 e^{-} \rightarrow 4 \mathrm{OH}^{-}$

The reduction of $\mathrm{O}_{2}$ (Eq. (12)) however can be hindered due to the low solubility of $\mathrm{O}_{2}$ in water [49]. As a result, the $\mathrm{H}_{2} \mathrm{O}$ reduction reaction (Eq. (11)) prevails at the cathode (-). The formation of $\mathrm{OH}^{-}$ions can lead to the breakdown of the steel passive layer which is then reduced to iron hydroxide $\left(\mathrm{Fe}(\mathrm{OH})_{2}\right)[18,19]$. Such a detrimental effect is similar to that of the depassivating agents such as chlorides, causing the breakdown of the steel passive layer. In summary, both positive and negative AC half cycles can enhance corrosion in SFRC, but via different mechanisms.

Fig. 9 and Fig. 10 indicate that the 1-hr AC interference shifted $E_{\text {corr }}$ more negatively and this agrees with values reported in the literature $[50,51]$. Steel fibre still demonstrates a high corrosion resistance to AC interference under chloride free conditions: $i_{\text {corr }}$ is $1.2 \mu \mathrm{A} / \mathrm{cm}^{2}$ which is similar to that obtained without AC interference (Fig. 8). The combined effect of AC voltage and high-concentration chloride $(0.8 \mathrm{~mol} / \mathrm{L})$ however significantly increases $i_{\text {corr }}$ to $87 \mu \mathrm{A} / \mathrm{cm}^{2}$; it will take approximately half a year to dissolve an entire steel fibre $(62 \mathrm{~mm}$ long and $0.75 \mathrm{~mm}$ in diameter) under such an environment according to Eq. (3), assuming no other causes for steel corrosion. In addition to the loss of steel reinforcement cross-sectional area, a loss in the bond performance between reinforcing steel and concrete, a loss of ductility in tension and a reduction in its shear strength, may also occur due to the corrosion of steel fibres [52-54]. 
These will jeopardize the mechanical performance of a steel fibre reinforced railway tunnel and eventually reduce its service life.

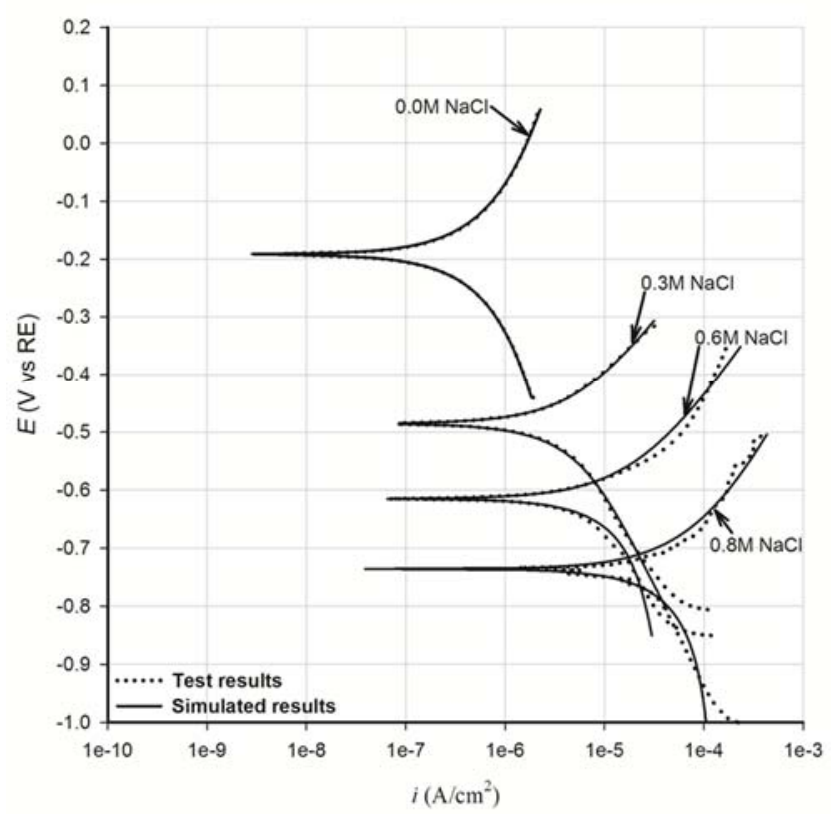

Fig. 9. Tafel polarization results after 1-hr AC interference (E-i curve)

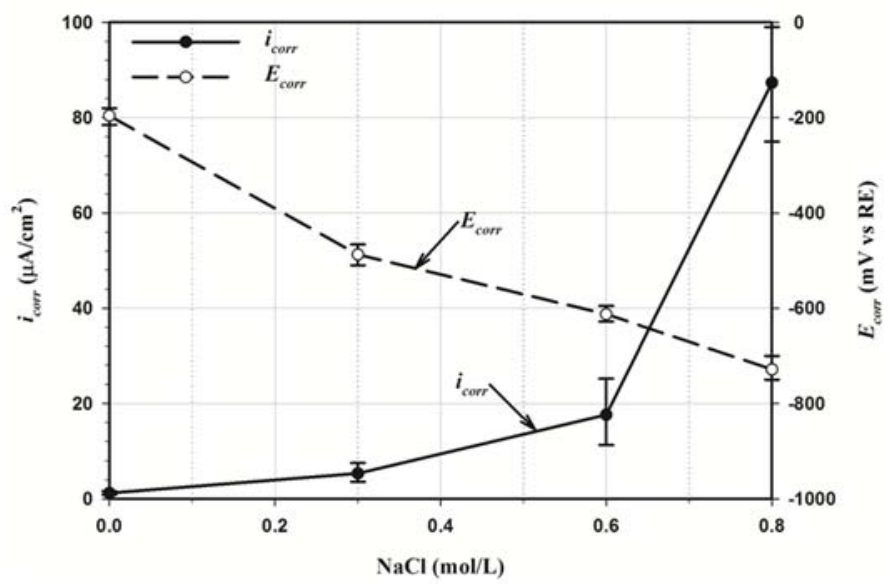

Fig. 10. Tafel polarization results (1-hr AC polarization)

In order to quantitatively evaluate the severity of $A C$-induced corrosion in SFRC, an electrochemical model was developed and shown in Fig. 11. It was used to model the corrosion processes experienced by steel fibres when both anodic and cathodic reactions are under charge-transfer control. This model consists of a resistor $\left(R_{c t}\right)$, representing the polarization resistance of steel fibres. In parallel with $R_{c t}$, a capacitor $(C)$ represents the admittance of the steel-mortar interface. Solution resistance of the electrolyte was represented as another resistor $\left(R_{s}\right)$. In this electrochemical model, the non-Faradaic current $I_{1}$, or capacitive current, does not involve any chemical reactions or charge transfer. The 
Faradaic current, $I_{2}$, is a direct measure of the rate of the redox reactions. The integration of $I_{2}$ (positive parts only) with respect to time will give a total electric charge, upon which the corrosion rate $(C R)$ can be calculated. According to the parallel circuit theory, an AC current $\left(I=I_{0} \cdot \sin \omega t\right)$ will lead to an identical voltage drop across $R_{c t}$ and $C$. The sum of the currents through each path, i.e. $I_{I}$ and $I_{2}$, is equal to the total current $(I)$. The above processes are represented as:

$R_{c t} \cdot I_{2}(t)=\frac{1}{C} \int I_{1} d t$

$I_{1}(t)+I_{2}(t)=I=I_{0} \cdot \sin \omega t$

The Faradaic current, $I_{2}$, is solved based on above equations as:

$I_{2}(t)=\frac{I_{0}}{\sqrt{1+\omega^{2} \cdot C^{2} \cdot R_{c t}^{2}}} \sin (\omega t-\theta)+\frac{\omega \cdot C \cdot R_{c t} \cdot I_{0}}{\omega^{2} \cdot C^{2} \cdot R_{c t}^{2}+1} \cdot e^{-\frac{t}{C \cdot R_{c t}}}$

Eq. (15) allows a quantitative assessment of $I_{2}$, which is directly related to the steel corrosion speed. $I_{2}$ is independent of $R_{s}$ but decreases with an increased frequency $(\omega)$ which agrees with the published experimental data $[21,55,56] . I_{2}$ is also affected by the admittance of both the electrical double layer $(C)$ and polarization resistance $\left(R_{c t}\right)$ : an increase in $C$ and $R_{c t}$ will reduce $I_{2}$ and thus the corrosion rate. In summary, the severity of AC interference is directly related to the kinetic parameters of steel fibres which can be obtained by conducting independent EIS analysis which is discussed in Section 3.3.

An increase in $C$ can be achieved by coating or insulating the steel fibre, despite this practice may allow more stray $\mathrm{AC}$ current to flow through the capacitor $(C)$ and enhance corrosion in surrounding infrastructure. A coating defect in the presence of $A C$ interference can also lead to serious local corrosion attack by forming a corrosion tubercle according to Nielsen and Cohn [57]. The study of AC-induced corrosion in coated steel fibre reinforced concrete is an area where ongoing research is being conducted.

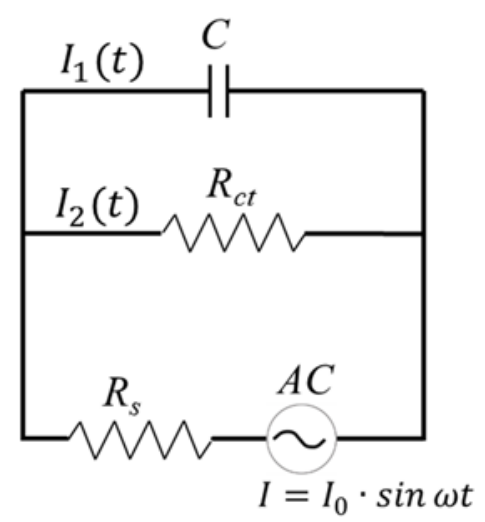

Fig. 11. Electrochemical modelling of $A C$-induced steel reinforcement corrosion 


\subsection{Effect of solid electrolyte (mortar) on AC induced corrosion in SFRC}

In order to verify that the results obtained using simulated concrete pore solutions were applicable for SFRC, a 72-hr AC interference test (between the age of 1 and 4 days after casting) was conducted using freshly cast mortar as a solid electrolyte (Fig. 5). EIS was conducted at the age of 1, 4, 10 and 50 days after casting and results are presented as the Bode phase plot (Fig. 12 (a) (d) and Fig. 13 (a) (d)), Bode |Z| plot (Fig. 12 (b) (e) and Fig. 13 (b) (e)) and Nyquist plot (Fig. 12 (c) (f) and Fig. 13 (c) (f)).

The Bode phase plot allows the phase shift angle $(\theta)$ to be plotted with regards to the excitation frequency $(\mathrm{Hz})$ on a logarithmic scale. All samples demonstrate a steady reduction in phase angle $(\theta)$ which drops at low frequencies between 0.1 and $1 \mathrm{~Hz}$. This indicates that the steel passive layer has been locally destroyed and a rust layer might have formed on the steel fibre surface due to the presence of either AC interference or chloride. The speed of the corrosion reactions is affected by the diffusion speed through the rust layer in such circumstances.

The Bode $|Z|$ plot allows the absolute values of the impedance $(|Z|)$ plotted against the logarithm of frequency (Hz). Fig. 12 (b) indicates that $|Z|$ drops significantly from about 30,000 $\Omega \cdot \mathrm{cm}^{2}$ at an excitation frequency of $0.1 \mathrm{~Hz}$ to $169 \Omega \cdot \mathrm{cm}^{2}$ at $10^{5} \mathrm{~Hz}$ under a chloride free environment. Steel membrane resistance $\left(R_{f}\right)$ and charge transfer resistance $\left(R_{c t}\right)$ govern the total impedance $(|Z|)$ at low frequencies; the bulk resistance of the solution $\left(R_{s}\right)$ is responsible for the total impedance $(|Z|)$ at high frequencies. The value of $|Z|$ obtained at $10^{5} \mathrm{~Hz}$ was 169 $\Omega \cdot \mathrm{cm}^{2}$, showing that $R_{s}$ is much smaller than $R_{c t}$. This finding agrees with the Nyquist plot: the real impedance $\left(Z^{\prime}\right)$ within the high frequency region $\left(10^{5} \mathrm{~Hz}\right)$ is $168 \Omega \cdot \mathrm{cm}^{2}$. A reduced $|Z|$ obtained at low frequencies is noticed after 72-hr AC interference with and without the presence of $\mathrm{NaCl}$ (Fig. 12 (b) (e)), indicating a reduction in $R_{c t}$. An increased corrosion rate is therefore expected according Eq. (15). $|Z|$ obtained at low frequencies (i.e. $0.1 \mathrm{~Hz}$ ) increases again at the age of 10 and 50 days and this can be attributed to the maturity of mortar, contributing to a dense steel-concrete interface and an enhanced corrosion resistance. The morphology characteristics of steel-concrete interfaces will be further discussed in Section 3.4.

Based on above interpretations of the EIS data, an equivalent circuit (Fig. 14) was developed to model the corrosion processes experienced by the steel fibre. In comparison to the electrochemical model proposed in Fig. 11, a membrane resistance $\left(R_{f}\right)$ and a steel passive layer capacitance $\left(C_{f}\right)$ were incorporated to represent the steel passive layer. In this model (Fig. 14), $R_{c t}$ and $R_{f}$ define the difficulty of a kinetically controlled electrochemical reaction. The capacitance of the steel passive layer $\left(C_{f}\right)$ and electrical double layer $\left(C_{d l}\right)$ were modelled as a constant phase element (CPE) which can better simulate the surface roughness and heterogeneousness of a double layer in comparison to a perfect capacitor [38]. The impedance $\left(Z_{C P E}\right)$ and capacitance $\left(\mathrm{C}_{C P E}\right)$ of a $\mathrm{CPE}$ is defined as:

$Z_{C P E}=\left(Y_{0}(j \omega)^{n}\right)^{-1}$ 
$C_{C P E}=\left(Y_{0} \omega_{m}^{n-1}\right) / \sin (n \pi / 2)$

Where $Y_{0}$ is governed by the capacitance of a pure capacitive electrode and $n$ represents the deviation of the capacitance from the ideal condition [38]. Best-fit curves based on the equivalent electronic circuit modelling (Fig. 14) are shown in Table 3 for the AC polarization group and Table 4 for the reference group. Table 3 indicates that the 4-day $R_{c t}$ reduces by almost one degree of magnitude from 37.3 to $3.5 \mathrm{k} \Omega \cdot \mathrm{cm}^{2}$, due to a combined effect of AC interference and chloride. This shows a high susceptibility for steel corrosion. The detrimental effect of chloride is less significant without $A C$ interference, as seen in the control group results (Table 4): $R_{c t}$ is $40.7 \mathrm{k} \Omega \cdot \mathrm{cm}^{2}$ which is even marginally higher than that obtained before the AC polarization, i.e. $37.8 \mathrm{k} \Omega \cdot \mathrm{cm}^{2}$. This shows the mitigation effect of the mortar. On the other hand, $R_{f}$ gradually increases with time, showing that corrosion products have been developed on the steel surface. This finding agrees with the $C_{d l}$ values in all groups: $C_{d l}$ is over $500 \times 10^{-6} \mathrm{~S} \cdot \mathrm{s}^{n} \cdot \mathrm{cm}^{-2}$, indicating that generalized corrosion might have occurred on the steel fibre surface [38,58]. As $R_{f}$ is much smaller than $R_{c t}$, only one time constant is obvious in the Bode Nyquist plots (Fig. 12 (c) (f)) and Fig. 13 (c) (f)).

The detrimental effect of $A C$ interference on the long-term corrosion resistance of SFRC becomes less significant, especially under a chloride-free environment. This is according to the 50-day EIS data: $R_{c t}$ is approximately one magnitude higher than that obtained at the age of 4 days, with and without the AC perturbation. The joint effect of chloride ( $2 \%$ by mass of cement) and AC interference also shows a mitigated effect: $R_{c t}$ is $296 \mathrm{k} \Omega \cdot \mathrm{cm}^{2}$ which is not too much less than that obtained for the reference group, i.e. $351 \mathrm{k} \Omega \cdot \mathrm{cm}^{2}$, as seen in Table 3 . This can be attributed to the beneficiary effect of the enhanced steel-mortar interface microstructure alongside the maturity of the mortar.

In summary, SFRC develops good corrosion resistance to AC interference under a chloridefree environment. Special attention is still needed for chloride contaminated SFRC, e.g. $\geq 2 \%$ $\mathrm{NaCl}$ (by mass of cement), at an early age (e.g. $\leq 4$ days). This study also shows the scope to develop a real-time railway tunnel health monitoring system based on electrical element parameter measurements. 


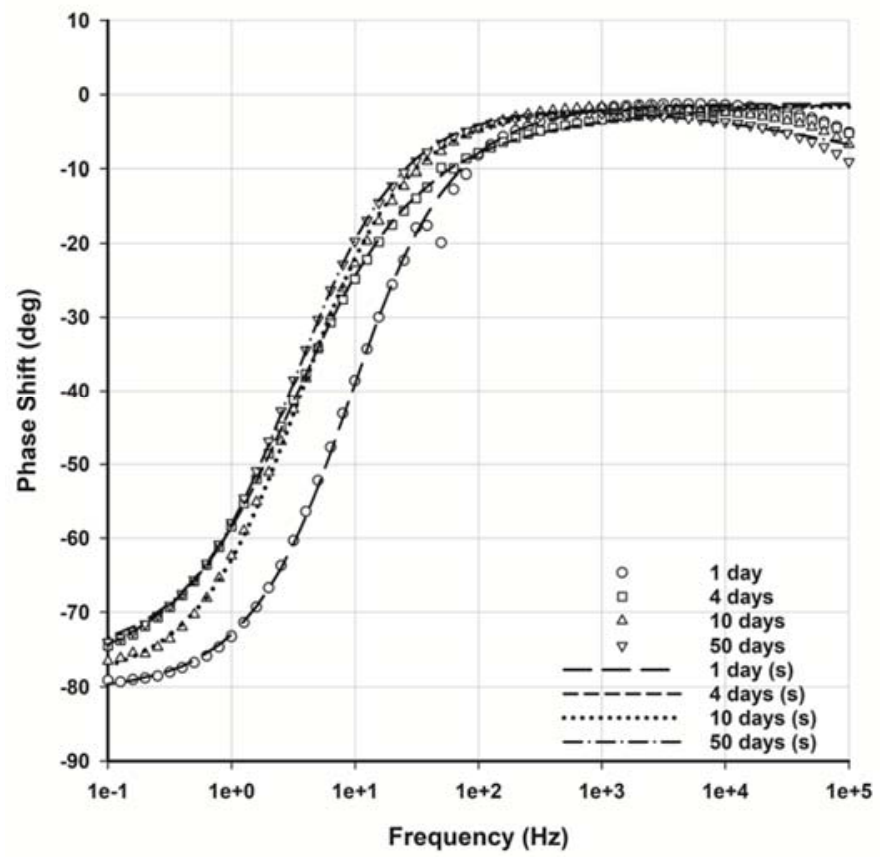

(a) Bode phase plot ( $0 \% \mathrm{NaCl}$ SFRC)

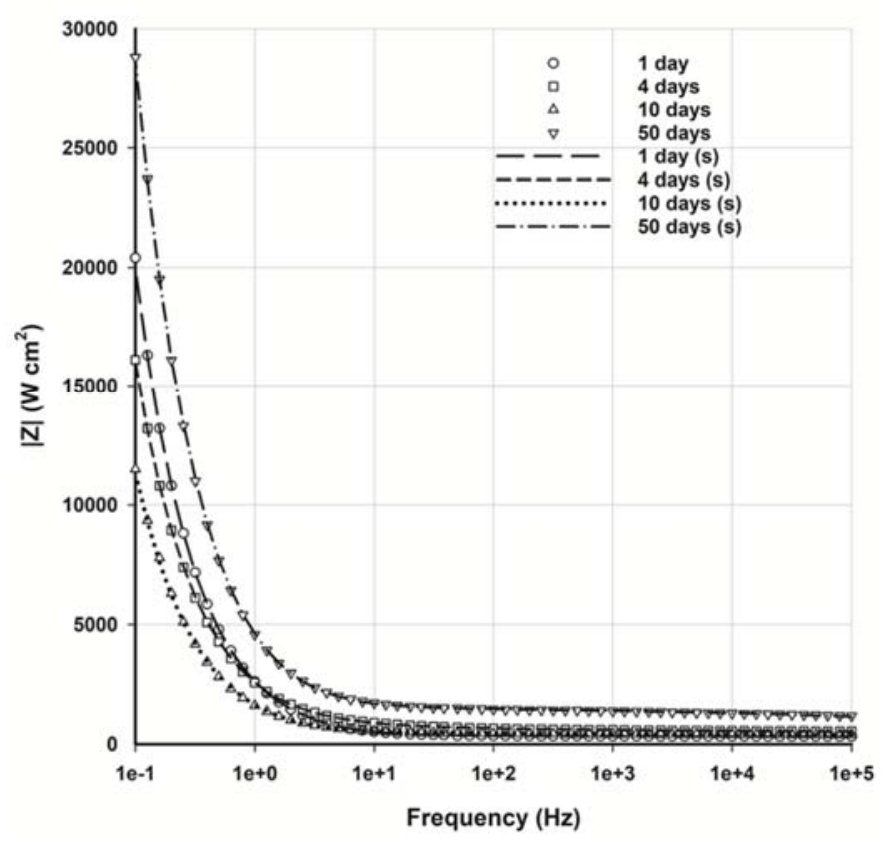

(b) Bode $|Z|$ plot ( $0 \% \mathrm{NaCl}$ SFRC) 


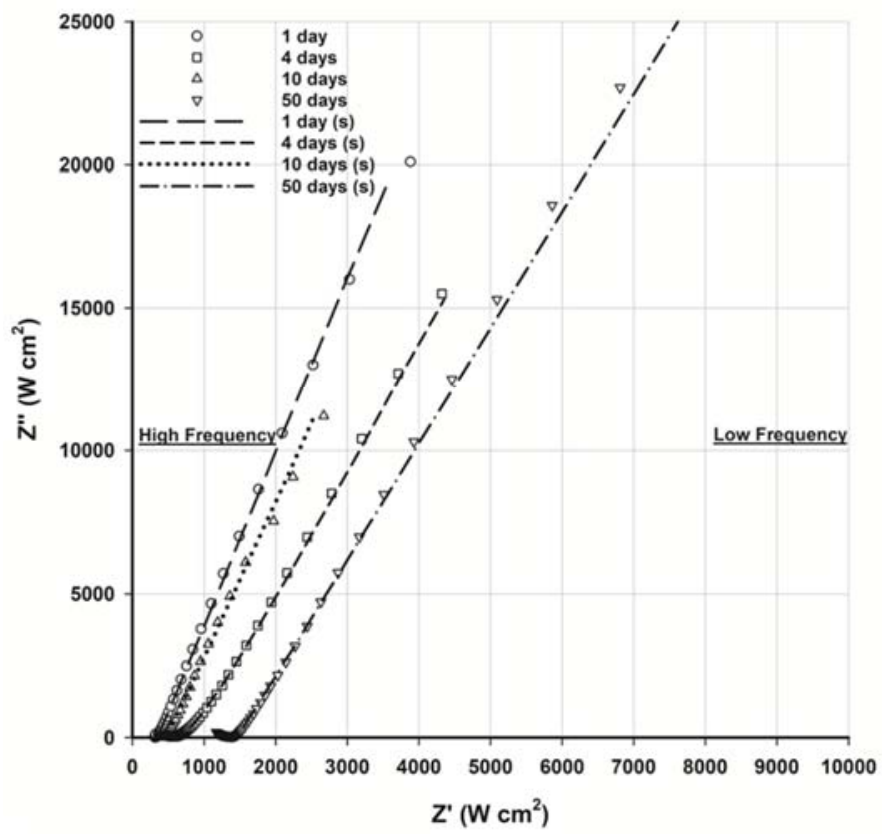

(c) Nyquist plot ( $0 \% \mathrm{NaCl}$ SFRC)

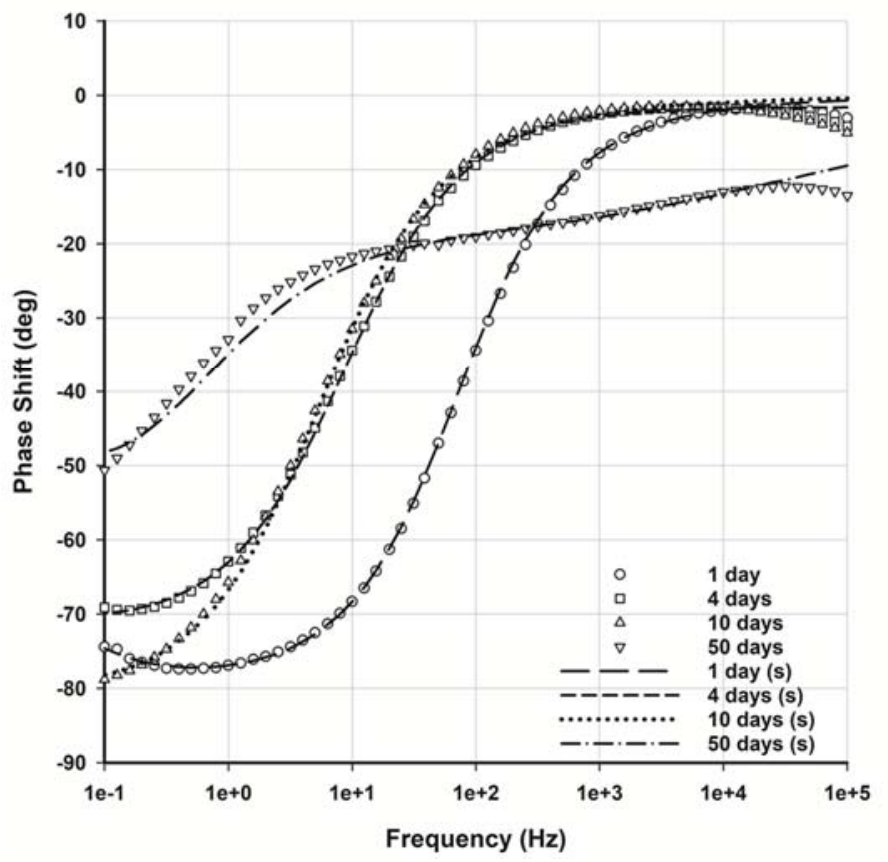

(d) Bode phase plot (2\% NaCl SFRC) 


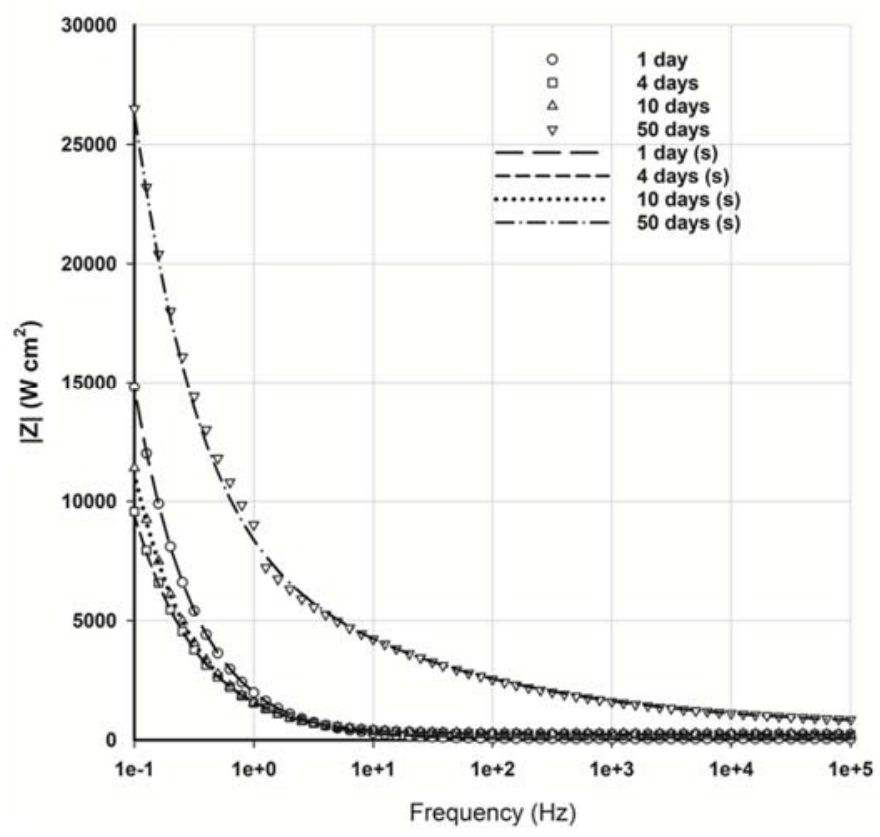

(e) Bode $|Z|$ plot $(2 \% \mathrm{NaCl}$ SFRC)

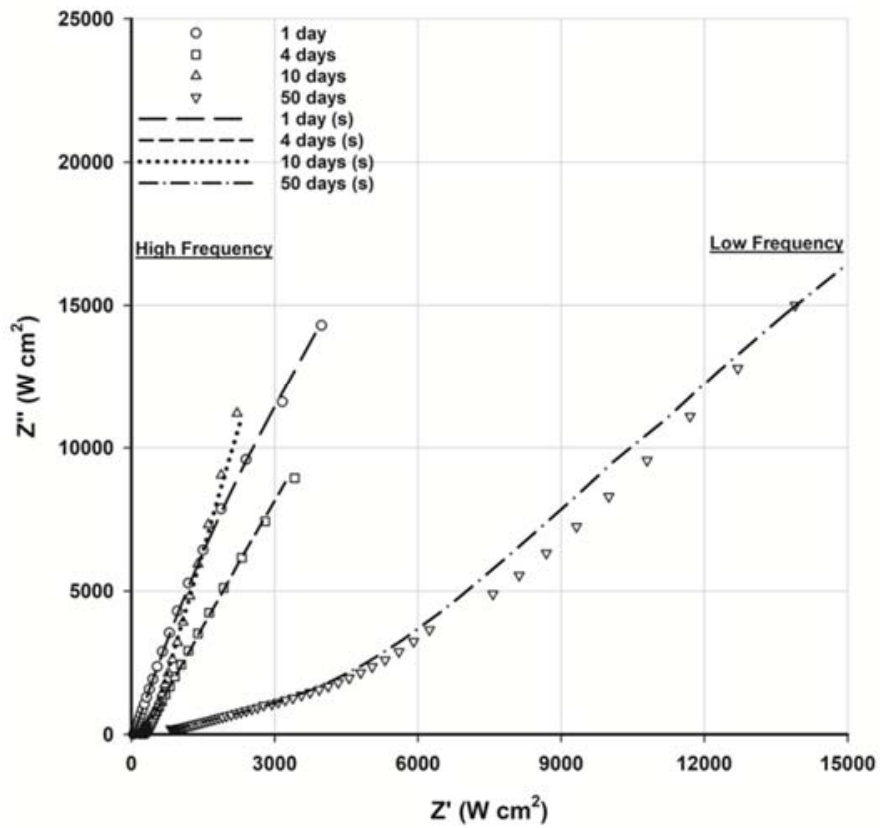

(f) Nyquist plot (2\% NaCl SFRC)

Fig. 12. EIS measurements - SFRC subjected to 72-hr $60 \mathrm{~mA} \mathrm{AC}$ current $(\mathrm{Hz})$ 


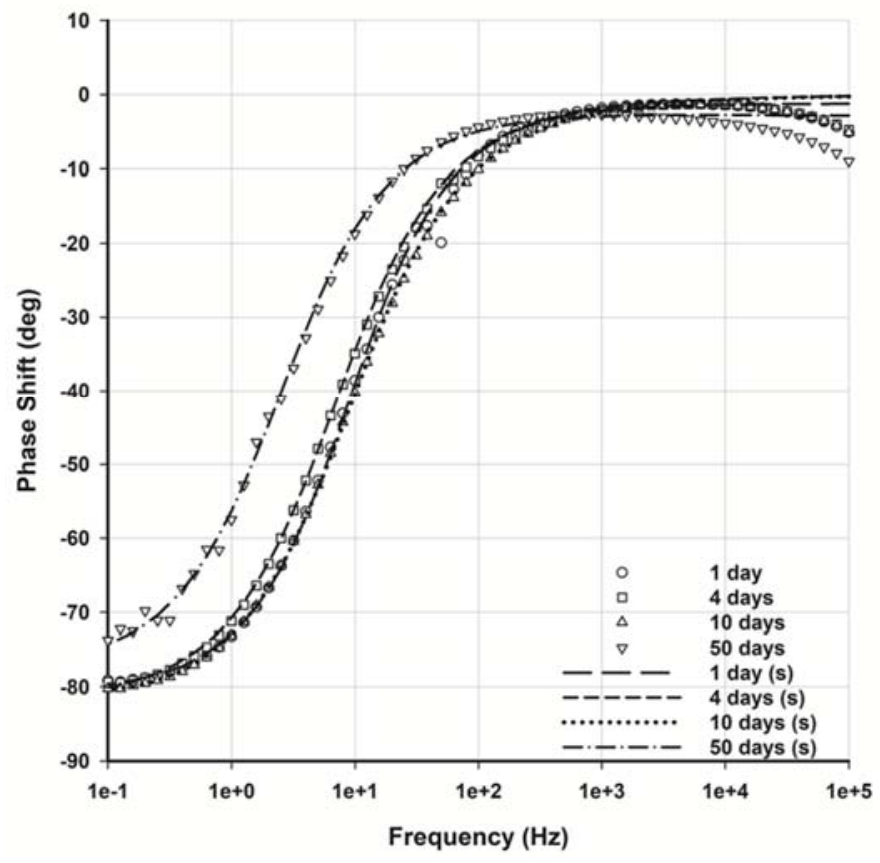

(a) Bode phase plot ( $0 \% \mathrm{NaCl}$ SFRC)

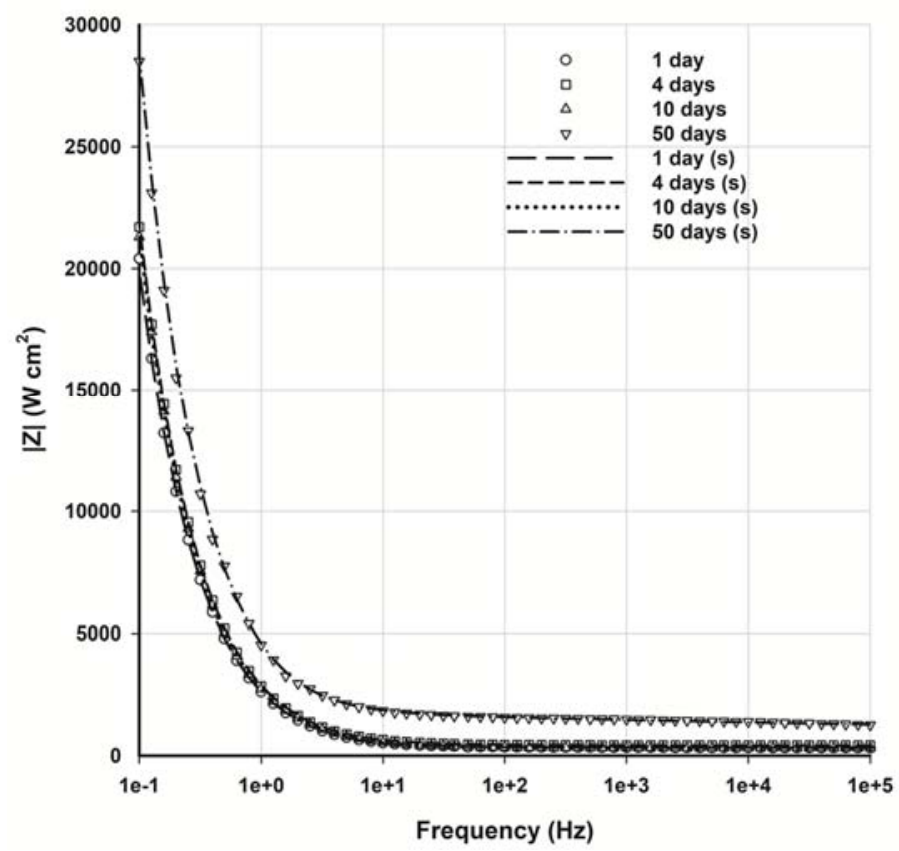

(b) Bode $|Z|$ plot ( $0 \% \mathrm{NaCl}$ SFRC) 


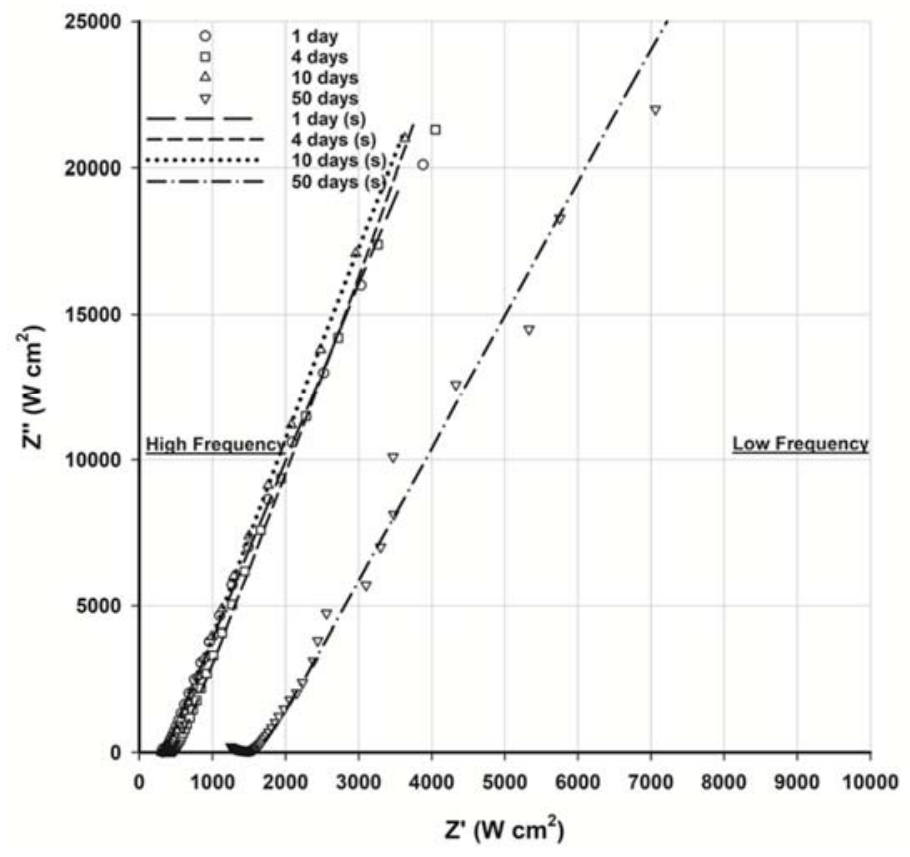

(c) Nyquist plot (0\% $\mathrm{NaCl}$ SFRC)

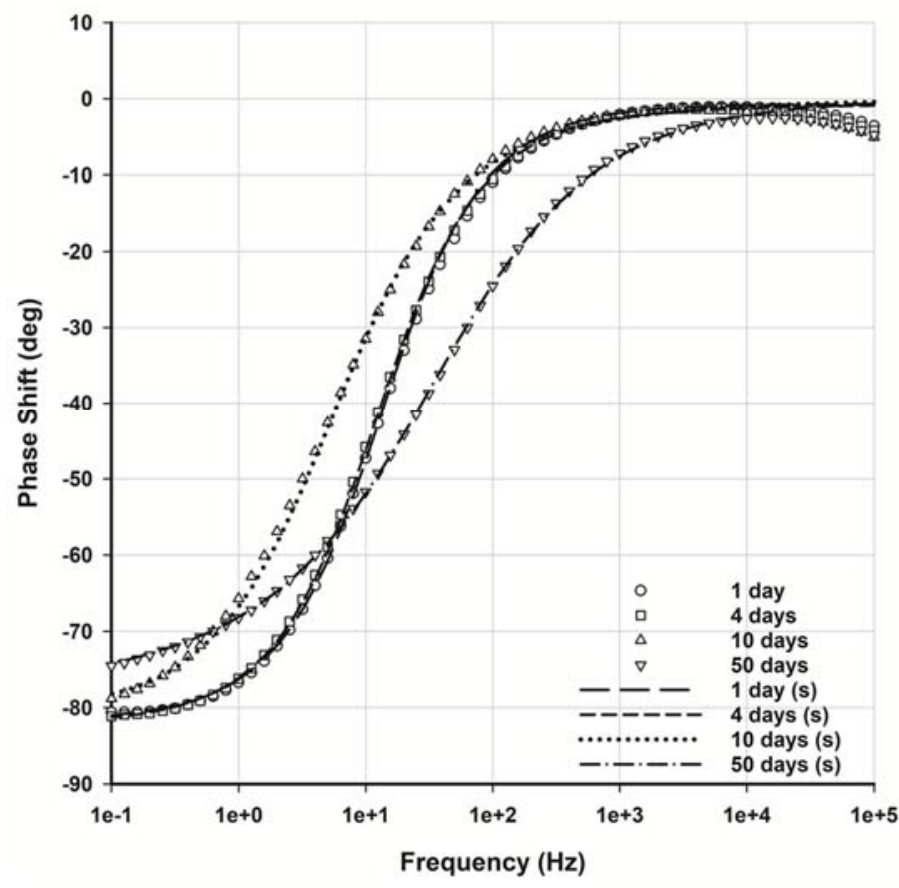

(d) Bode phase plot ( $2 \% \mathrm{NaCl}$ SFRC) 


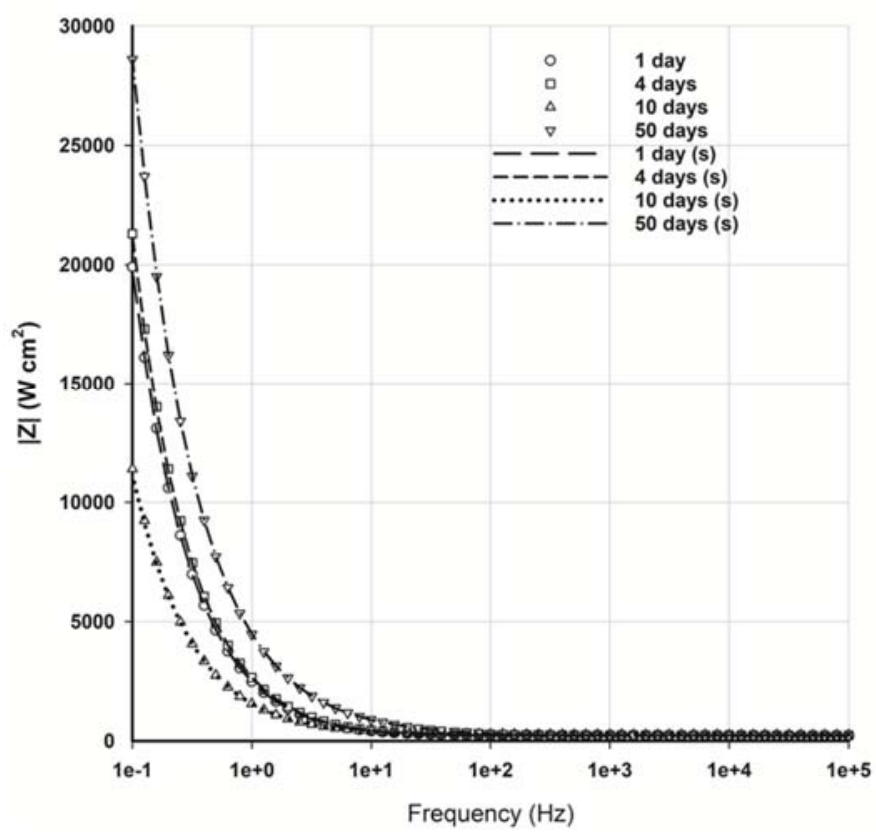

(e) Bode $|Z|$ plot (2\% NaCl SFRC)

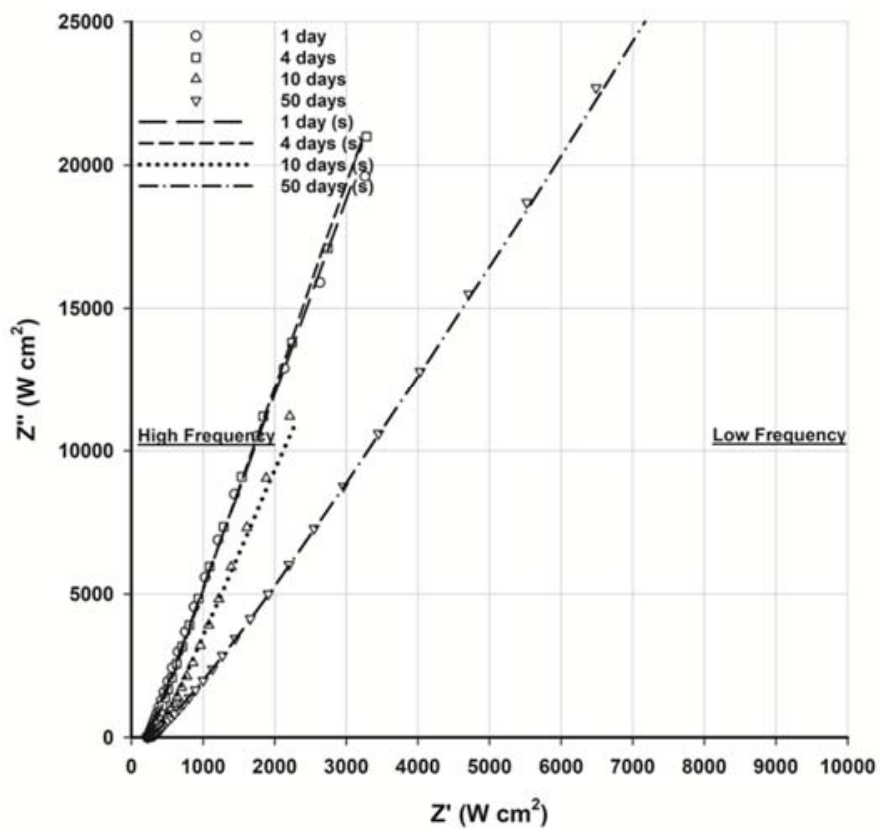

(f) Nyquist plot (2\% $\mathrm{NaCl}$ SFRC)

Fig. 13. EIS measurements - reference group 


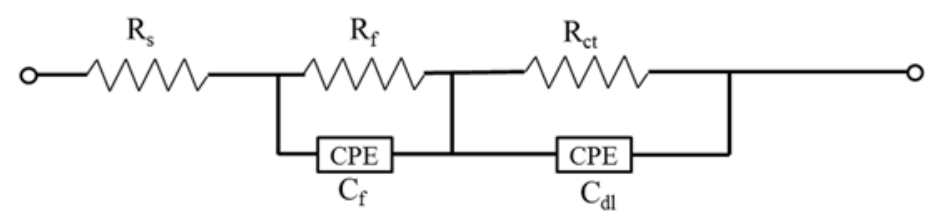

Fig. 14. EIS equivalent electrical circuit

Table 3 EIS best-fit results - SFRC subjected to 72-hr 60 mA AC interference

\begin{tabular}{|c|c|c|c|c|c|c|c|c|}
\hline & $\begin{array}{l}\text { OCP } \\
(\mathrm{mV})\end{array}$ & $\begin{array}{l}R_{S} \\
\left(\Omega \cdot \mathrm{cm}^{2}\right)\end{array}$ & $\begin{array}{l}R_{f} \\
\left(\Omega \cdot \mathrm{cm}^{2}\right)\end{array}$ & $\begin{array}{l}Y_{0 f} \\
\left(10^{-6} \mathrm{~S} \cdot \mathrm{s}^{\mathrm{n}} \cdot \mathrm{cm}^{-2}\right)\end{array}$ & $n_{f}$ & $\begin{array}{l}R_{c t} \\
\left(10^{3} \Omega \cdot \mathrm{cm}^{2}\right)\end{array}$ & $\begin{array}{l}Y_{0 d l} \\
\left(10^{-6} \mathrm{~S} \cdot \mathrm{s}^{\mathrm{n}} \cdot \mathrm{cm}^{-2}\right)\end{array}$ & $n_{d l}$ \\
\hline $0 \% \mathrm{NaCl}$ 1-day & -312 & 86 & 231 & 65 & 0.37 & 48.7 & 586 & 0.90 \\
\hline $0 \% \mathrm{NaCl} 4$-day* & -288 & 50 & 278 & 96 & 0.34 & 34.7 & 860 & 0.97 \\
\hline $0 \% \mathrm{NaCl} 10-$ day $^{*}$ & -302 & 52 & 481 & 66 & 0.48 & 49.4 & 678 & 0.88 \\
\hline $0 \% \mathrm{NaCl} 50$-day* & -197 & 72 & 1725 & 36 & 0.26 & 275.1 & 512 & 0.88 \\
\hline 2\% NaCl 1-day & -485 & 32 & 162 & 101 & 0.89 & 37.3 & 1024 & 0.85 \\
\hline $2 \% \mathrm{NaCl} 4$-day* & -452 & 67 & 199 & 154 & 0.83 & 3.5 & 2474 & 0.98 \\
\hline $2 \% \mathrm{NaCl} 10$-day* & -320 & 156 & 492 & 111 & 0.88 & 3.7 & 1369 & 0.87 \\
\hline $2 \% \mathrm{NaCl} 50-$ day $^{*}$ & -333 & 64 & 2956 & 27 & 0.26 & 295.6 & 547 & 0.60 \\
\hline
\end{tabular}

* Subjected to $60 \mathrm{~mA} \mathrm{AC}$ currents between the age of 1 and 4 days

Table 4 EIS best-fit results - SFRC without pre-exposure to stray AC (reference group)

\begin{tabular}{|c|c|c|c|c|c|c|c|c|}
\hline & $\begin{array}{l}\text { OCP } \\
(\mathrm{mV})\end{array}$ & $\begin{array}{l}R_{S} \\
\left(\Omega \cdot \mathrm{cm}^{2}\right)\end{array}$ & $\begin{array}{l}R_{f} \\
\left(\Omega \cdot \mathrm{cm}^{2}\right)\end{array}$ & $\begin{array}{l}Y_{0 f} \\
\left(10^{-6} \mathrm{~S} \cdot \mathrm{s}^{\mathrm{n}} \cdot \mathrm{cm}^{-2}\right)\end{array}$ & $n_{f}$ & $\begin{array}{l}R_{c t} \\
\left(10^{3} \Omega \cdot \mathrm{cm}^{2}\right)\end{array}$ & $\begin{array}{l}Y_{\text {Odl }} \\
\left(10^{-6} \mathrm{~S} \cdot \mathrm{s}^{\mathrm{n}} \cdot \mathrm{cm}^{-2}\right)\end{array}$ & $n_{d l}$ \\
\hline $0 \% \mathrm{NaCl}$ 1-day & -350 & 180 & 262 & 219 & 0.70 & 55.3 & 761 & 0.90 \\
\hline $0 \% \mathrm{NaCl}$ 4-day & -367 & 381 & 257 & 70 & 0.91 & 51.8 & 451 & 0.91 \\
\hline $0 \% \mathrm{NaCl} 10$-day & -324 & 300 & 255 & 121 & 0.42 & 79.5 & 723 & 0.91 \\
\hline $0 \% \mathrm{NaCl} 50$-day & -203 & 50 & 741 & 20 & 0.49 & 298.0 & 617 & 0.81 \\
\hline $2 \% \mathrm{NaCl} 1$-day & -486 & 255 & 72 & 100 & 0.99 & 37.8 & 502 & 0.89 \\
\hline $2 \% \mathrm{NaCl}$ 4-day & -259 & 217 & 306 & 494 & 0.57 & 40.7 & 720 & 0.91 \\
\hline $2 \% \mathrm{NaCl} 10-$ day & -387 & 245 & 500 & 1850 & 0.38 & 18.5 & 758 & 0.88 \\
\hline $2 \% \mathrm{NaCl} 50$-day & -160 & 216 & 1644 & 338 & 0.52 & 351.1 & 514 & 0.88 \\
\hline
\end{tabular}

\subsection{Morphology characteristics of AC corrosion in SFRC}

SFRC specimens were cut at the age of 50 days as seen in Fig. 6 to expose the steel fibre cross sections. Based upon a visual observation, a rust layer was observed the steel fibre surface exposed to $2 \% \mathrm{NaCl}$ (by mass of cement), especially under $\mathrm{AC}$ interference. There was no obvious sign of corrosion in chloride-free SFRC samples, indicating the mitigation effect of a solid electrolyte. The morphology of the steel fibre cross sections was further investigated using the Zeiss EVO50 SEM-EDS and results are shown in Fig. 15.

Scanning Electron Microscope (SEM) images of the steel fibres indicate an enhancement of corrosion in the $\mathrm{AC}$ environment with higher chloride content in comparison to the reference group. Note that the steel fibre is deformed slightly by the cutting process and striations from the cutting process can be seen on the surface of some of the fibres. Even so the darkening due to corrosion of the steel fibre exposed to AC and chloride (i.e. Fig. 15 (c)) forms a clear 
difference in comparison to the other samples. There is also evidence of minor pitting corrosion primarily on the fibre-mortar interface in the reference group in the presence of chloride (i.e. Fig. 15 (d)).

Full spectrum EDS chemical analysis was carried out along the mid plane of the steel fibres as seen in Fig. 15: the solid lines indicate the scan line for chemical analysis. The data for iron and oxygen are presented in Fig. 16. The number of iron counts is the highest for the reference group with $0 \% \mathrm{NaCl}$. The number of iron counts is reduced slightly in the $\mathrm{AC}$ environment with $0 \% \mathrm{NaCl}$ and in the reference group with $2 \% \mathrm{NaCl}$. They are however greatly reduced in the $\mathrm{AC}$ environment with $2 \% \mathrm{NaCl}$, indicating serious steel corrosion. oxygen is present in both the steel fibre and the surrounding mortar. The oxygen concentration in the mortar varies depending on the material in direct contact with the steel fibre. However the variation in oxygen concentrations provides useful information about the formation of corrosion products on the steel surface. For instance, the oxygen concentration in the reference group containing $0 \% \mathrm{NaCl}$ is low inside the steel fibre, with a slight increase towards the edge of the fibre. The $0 \% \mathrm{NaCl}$ AC-interfered group displays a similar pattern of increase in oxygen concentration. The $2 \% \mathrm{NaCl} A C$-interfered group however shows the opposite effect with a peak towards the center of the fibre further indicating the enhanced corrosion of the fibre. The increase in oxygen content from the center to the edge of the fibres, indicates the early stages of corrosion. In particular, the $2 \% \mathrm{NaCl}$ reference group and the $0 \% \mathrm{NaCl} \mathrm{AC}$ group show a higher level of oxygen than the $0 \% \mathrm{NaCl}$ reference group. The data for calcium are also presented in Fig. 16. Calcium can be taken as the indicator of the concrete boundary (excluding where sand is present). It also shows where small grains of concrete dust have been embedded onto the steel fibre surface during the cutting process. Some of these match highs in the oxygen count results as the concrete particles also contain oxygen. The ability to identify these fine particles indicates that the noise to signal ratio and the resolution for the chemical analysis is good.

AC-induced pitting corrosion in SFRC shows a random or stochastic pattern in its occurrence. This can be attributed to the material inhomogeneity, e.g. variations in the fibre diameter, chemical composition and possible surface defects. The oxygen and chloride concentrations in the solid electrolyte (mortar) can also be variable at different ends of the steel fibre. Such a steel-concrete interfacial damage can reduce the bond strength which can lead to a slip and separation from concrete during the service life of a tunnel made of SFRC and eventually reduce the service life of the railway system. 


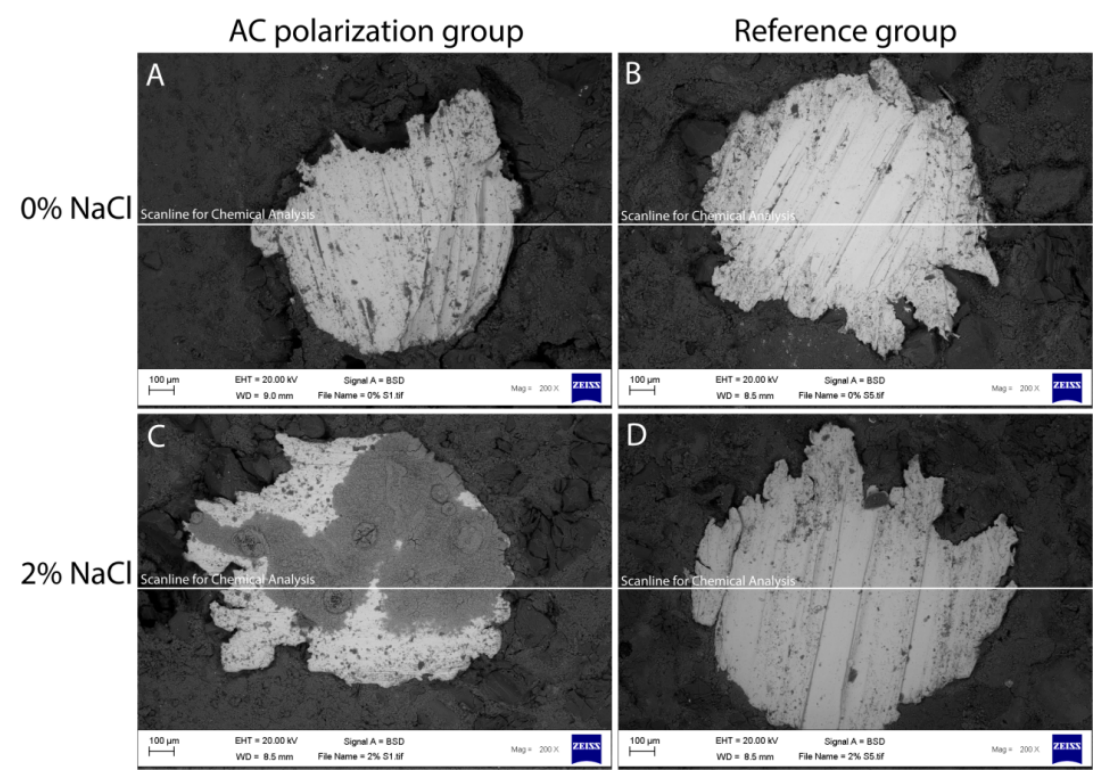

Fig. 15. Electron microscope images of steel fibres in concrete. $A$ and $B$ have $0 \% \mathrm{NaCl} ; \mathrm{C}$ and $D$ have $2 \% \mathrm{NaCl}$. $A$ and $C$ are exposed to $A C$ interference, $B$ and $D$ are obtained from the reference group

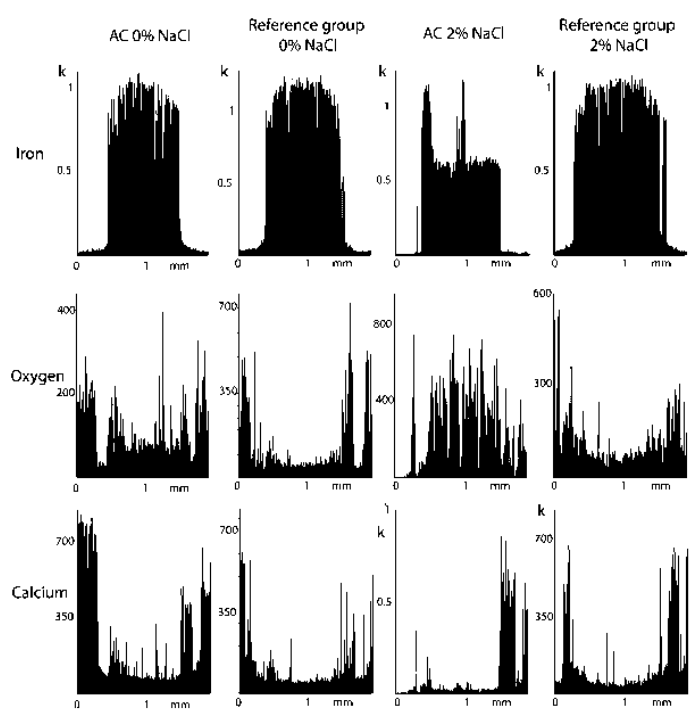

Fig. 16. Chemical analysis (EDS) for the scanline demonstrated in Fig. 15 showing iron, oxygen and calcium relative concentrations; $\mathrm{k}$ means thousands

\section{Conclusion}

This paper discusses the corrosion mechanism of steel fibre reinforced concrete (SFRC) under stray AC environments. SFRC develops good corrosion resistance to AC interference under a chloride-free environment. Special attention is still needed for chloride contaminated SFRC, e.g. $\geq 2 \% \mathrm{NaCl}$ (by mass of cement) or $0.3 \mathrm{~mol} / \mathrm{L}$, especially at an early age (e.g. $\leq 4$ days). A coated steel fibre surface may enhance its corrosion resistance, despite this practice may allow more stray AC current to flow through the SFRC specimen and leading to corrosive attack to surrounding infrastructures. This study also shows the scope to develop a real-time 
railway tunnel health monitoring system based on the electrical element parameter measurements (e.g. $R_{c t}$ and $C_{d l}$ ).

The SEM and EDS data indicate that corrosion is greatly enhanced in the AC environment due to the presence of $2 \% \mathrm{NaCl}$. This causes some concerns for stray current in chloride rich environments. In addition from the measurement of the oxygen concentrations across the cut steel fibres, there is evidence that the $A C$ environment on its own produces equivalent corrosion to the presence of $2 \% \mathrm{NaCl}$ in the reference group. This indicates the importance of stray current in understanding steel fibre corrosion.

With the development of high-speed rail, more conditions for interference between AC traction systems and traditional DC traction systems are expected. The effect of such $A C$ and DC interference conditions on the polarization behaviour of steel fibres will be considered in future investigations.

\section{Acknowledgements}

The author gratefully acknowledges Colin Eddie, John Booth and John Greenhalgh for their guidance and advice. In particular, the author wishes to thank Lu for her patience and support over these years.

\section{References}

[1] Wikipedia, $25 \mathrm{kV}$ AC railway electrification. https://en.wikipedia.org/wiki/25_kV_AC_railway_electrification, 2017 (accessed 29 June 2018).

[2] Crossrail, Europe's largest construction project. http://www.crossrail.co.uk/construction/, 2017 (accessed 27 June 2017).

[3] Railway-technology, High Speed 2 (HS2) railway. http://www.railwaytechnology.com/projects/high-speed-2-hs2l, 2017 (accessed 27 June 2017).

[4] Wikipedia, Turin-Lyon high-speed railway. https://en.wikipedia.org/wiki/Turin\%E2\%80\%93Lyon_high-speed_railway, 2017 (accessed 29 June 2018).

[5] Wikipedia, Gotthard Base Tunnel. https://en.wikipedia.org/wiki/Gotthard_Base_Tunnel, 2016 (accessed 29 June 2018).

[6] L. Bertolini, M. Carsana, P. Pedeferri, Corrosion behaviour of steel in concrete in the presence of stray current, Corrosion Science, 49 (2007) 1056-1068.

[7] National Physical Laboratory (UK), Estimate of annual costs attributable to corrosion of reinforced concrete structures in the United Kingdom. www.npl.co.uk, 2015 (accessed 18 November 2016).

[8] A. Steel, Design standards stray current management, Office of Rail Regulation, 2010.

[9] W. Prinz, AC Induced Corrosion on Cathodically Protected Pipelines, Sandown Park, England, 1992.

[10] I. Ragault, Electrical lines on polyethylene coated steel gas pipelines, NACE International, San Diego, California, USA, 1998.

[11] R.G. Wakeling, R.A. Gummow, S.M. Segall, AC corrosion - case history, test procedures \& mitigation, NACE International, San Diego, California, USA, 1998.

[12] BSI, BS EN 15280:2013 Evaluation of A.C. corrosion likelihood of buried pipelines applicable to cathodically protected pipelines, British Standards Institution, 2013.

[13] D. Kuang, Y.F. Cheng, Understand the AC induced pitting corrosion on pipelines in both high pH and neutral pH carbonate/bicarbonate solutions, Corrosion Science, 85 (2014) 304310. 
[14] A.Q. Fu, F.Y. Cheng, F.Y. Cheng, Effect of alternating current on corrosion and effectiveness of cathodic protection of pipelines, Canadian Metallurgical Quarterly, 51 (2012) 81-90.

[15] K. Tang, S. Wilkinson, G. Beattie, Effects of curing temperature on the hydration of GGBS blended concrete and the use of electron microscope particle analysis Advances in Cement Research, 29 (2017) 322-335.

[16] ACl, Building Code Requirements for Structural Concrete (ACl 318-08) and Commentary, American Concrete Institute, Farmington Hills, U.S.A., 2008.

[17] V. Marcos-Meson, A. Michel, A. Solgaard, G. Fischer, C. Edvardsen, T.L. Skovhus, Corrosion resistance of steel fibre reinforced concrete - A literature review, Cement and Concrete Research, 103 (2018) 1-20.

[18] A. Brenna, A proposal of AC corrosion mechanism of carbon steel in cathodic protection condition (PhD thesis), Politecnico di Milano, 2011.

[19] C. Cao, Principles of electrochemistry of corrosion, Chemical industry Press, Beijing, China, 2008.

[20] S.B. Lalvani, X. Lin, A revised model for predicting corrosion of materials induced by alternating voltages, Corrosion Science, 38 (1996) 1709-1719.

[21] L.W. Wang, X.H. Wang, Z.Y. Cui, Z.Y. Liu, C.W. Du, X.G. Li, Effect of alternating voltage on corrosion of $X 80$ and $X 100$ steels in a chloride containing solution - Investigated by AC voltammetry technique, Corrosion Science, 86 (2014) 213-222.

[22] R.W. Bosch, W.F. Bogaerts, A theoretical study of AC-induced corrosion considering diffusion phenomena, Corrosion Science, 40 (1998) 323-336.

[23] Y. Guo, H. Tan, T. Meng, D. Wang, S. Liu, Effects of alternating current interference on the cathodic protection for API 5L X60 pipeline steel, Journal of Natural Gas Science and Engineering, 36 (2016) 414-423.

[24] C. Wen, J. Li, S. Wang, Y. Yang, Experimental study on stray current corrosion of coated pipeline steel, Journal of Natural Gas Science and Engineering, 27 (2015) 1555-1561.

[25] L.Y. Xu, X. Su, Z.X. Yin, Y.H. Tang, Y.F. Cheng, Development of a real-time AC/DC data acquisition technique for studies of AC corrosion of pipelines, Corrosion Science, 61 (2012) 215-223.

[26] S. Goidanich, L. Lazzari, M. Ormellese, AC corrosion - Part 2: Parameters influencing corrosion rate, Corrosion Science, 52 (2010) 916-922.

[27] Federation internationale du beton, Fib Model Code for Concrete Structures 2010, Ernst \& Sohn, 2013.

[28] J. Greenhalgh, 20 years of fibre concrete linings in the UK.

https://www.tunneltalk.com/Fibrecrete-Oct10-20-years-of-fibrecrete-in-the-UK.php, 2010 (accessed 8 July 2018).

[29] M. Burgess, H. Davies, Channel tunnel rail link section 2: Thames tunnel, Proceedings of the Institution of Civil Engineers: Civil Engineering, 160 (2007) 14-18.

[30] L. Lin, Study of the influence to the steel fiber concrete durability due to the stray current (Master thesis), China University of Mining and Technology Beijing, 2005.

[31] Tunnel-online, Steel-fibre-reinforced segmental linings: State-of-the-art and completed projects. http://www.tunnel-online.info/en/artikel/tunnel 2011-01 Steel-fibrereinforced segmental linings State-of-the-art and completed 1076896.html, 2011 (accessed 14 October 2018).

[32] A. W., C. M., Design of Steel Fibre Reinforced Segmental Lining for the Gold Coast Desalination Tunnels, Melbourne, Australia, 2008.

[33] T. Kasper, C. Edvardsen, G. Wittneben, D. Neumann, Lining design for the district heating tunnel in Copenhagen with steel fibre reinforced concrete segments, Tunnelling and underground space technology, 23 (2008) 574-587.

[34] C. Edvardsen, W. Nell, M. Eberli, S. Müller, Steel Fibre Reinforced Concrete for Tunnel Lining Segments, Tunnel 2018 (2018) 60-65.

[35] P. Keen, R. Phillpotts, Low cost electrification for branch lines, DeltaRail, Derby, 2010.

[36] W. Li, The monitor and control system of stray current corrosion in metro, Urban mass transit, 6 (2003) 48-52.

[37] A. Yadav, Traction choices: overhead ac vs third rail dc.

http://www.railjournal.com/index.php/rolling-stock/traction-choices-overhead-ac-vs-third-raildc.html, 2013 (accessed 17 September 2018).

[38] C.Q. Ye, R.G. Hu, S.G. Dong, X.J. Zhang, R.Q. Hou, R.G. Du, C.J. Lin, J.S. Pan, EIS analysis on chloride-induced corrosion behavior of reinforcement steel in simulated 
carbonated concrete pore solutions, Journal of Electroanalytical Chemistry, 688 (2013) 275281.

[39] K. Tang, Stray current induced corrosion to steel fibre reinforced concrete, Cement and Concrete Research, 100 (2017) 445-456.

[40] J. Shi, W. Sun, J. Jiang, Y. Zhang, Influence of chloride concentration and prepassivation on the pitting corrosion resistance of low-alloy reinforcing steel in simulated concrete pore solution, Construction and Building Materials, 111 (2016) 805-813.

[41] A. Brenna, S. Beretta, F. Bolzoni, M. Pedeferri, M. Ormellese, Effects of AC-interference on chloride-induced corrosion of reinforced concrete, Construction and Building Materials, 137 (2017) 76-84.

[42] X. Wan, F.H. Wittmann, T. Zhao, H. Fan, Chloride content and $\mathrm{pH}$ value in the pore solution of concrete under carbonation, Journal of Zhejiang University, 14 (2012) 71-78.

[43] W. Aperador, A. Delgado, E. Vera, EIS monitoring of embedded steel in alkali activated concrete exposed to carbonation, Revista Ingeniería de Construcción, 26 (2011) 81-94.

[44] J.M. Deus, B. Díaz, L. Freire, X.R. Nóvoa, The electrochemical behaviour of steel rebars in concrete: an Electrochemical Impedance Spectroscopy study of the effect of temperature, Electrochimica Acta, 131 (2014) 106-115.

[45] R.G. Duarte, A.S. Castela, R. Neves, L. Freire, M.F. Montemor, Corrosion Behavior of Stainless Steel Rebars Embedded in Concrete: an Electrochemical Impedance Spectroscopy Study, Electrochimica Acta, 124 (2014) 218-224.

[46] X. Liu, Z. Shi, G. Xu, G. Song, H. Lin, C. Cao, The corrosion behaviour of reinforced concrete using EIS tests, Corrosion science and protection technology, 11 (1999) 161-164.

[47] Y.A.N. Maocheng, X.U. Jin, Y.U. Libao, W.U. Tangqing, S.U.N. Cheng, K.E. Wei, EIS analysis on stress corrosion initiation of pipeline steel under disbonded coating in near-neutral pH simulated soil electrolyte, Corrosion Science, 110 (2016) 23-34.

[48] Gamry, Gamry Echem Analyst. http://www.gamry.com/support/software/dc105-dccorrosion-software/, 2015 (accessed 20 October 2018).

[49] P.R. Roberge, Corrosion engineering: principles and practice, McGraw-Hill, 2008. [50] S. Goidanich, L. Lazzari, M. Ormellese, AC corrosion - Part 1: Effects on overpotentials of anodic and cathodic processes, Corrosion Science, 52 (2010) 491-497.

[51] D.-T. Chin, P. Sachdev, Corrosion by alternating current: polarization of mild steel in neutral electrolytes, Electrochemical science and technology, 130 (1983) 1714-1718.

[52] N.A. Farhan, M.N. Sheikh, M.N.S. Hadi, Experimental Investigation on the Effect of Corrosion on the Bond Between Reinforcing Steel Bars and Fibre Reinforced Geopolymer Concrete, Structures, 14 (2018) 251-261.

[53] G. Chen, M.N.S. Hadi, D. Gao, L. Zhao, Experimental study on the properties of corroded steel fibres, Construction and Building Materials, 79 (2015) 165-172.

[54] M. Zhu, C. Du, X. Li, Z. Liu, S. Wang, J. Li, D. Zhang, Effect of AC current density on stress corrosion cracking behavior of X80 pipeline steel in high $\mathrm{pH}$ carbonate/bicarbonate solution, Electrochimica Acta, 117 (2014) 351-359.

[55] W.W. Qiu, M. Pagano, G. Zhang, S.B. Lalvani, A periodic voltage modulation effect on the corrosion oF Cu-Ni Alloy, Corrosion Science, 37 (1995) 97-110.

[56] M. Yunovich, N.G. Thompson, AC Corrosion: Mechanism and Proposed Model, The American Society of Mechanical Engineers (ASME), Calgary, Alberta, Canada, 2004, pp. 183-195.

[57] V. Nielsen, P. Cohn, AC corrosion and electrical equivalent diagrams, European

Committee for the Study of Corrosion and Protection of Pipes and Pipelines Systems Drinking Water,Waste Water,Gas and Oil, UK, 2000.

[58] M. Saremi, E. Mahallati, A study on chloride-induced depassivation of mild steel in simulated concrete pore solution, Cement and Concrete Research, 32 (2002) 1915-1921. 